\title{
Circularly Polarized Luminescence from Enantiopure C2- Symmetrical Tetrakis(2-pyridylmethyl)-1,2-diaminocyclohexane Lanthanide Complexes
}

\author{
Kaitlynn M. Ayers, ${ }^{1}$ Nathan D. Schley, ${ }^{2}$ Gaël Ung*, ${ }^{1}$ \\ ${ }^{1}$ Department of Chemistry, University of Connecticut, Storrs, Connecticut 06269, United States \\ ${ }^{2}$ Department of Chemistry, Vanderbilt University, Nashville, Tennessee 37235, United States
}

E-mail: gael.ung@uconn.edu

\section{Contents}

NMR

Samarium[tetrakis(2-pyridylmethyl)diaminocyclohexane]tris(triflate)............ ${ }^{1} \mathrm{H}: \mathrm{S3}$

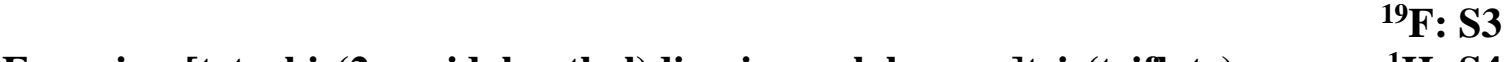

Europium[tetrakis(2-pyridylmethyl)diaminocyclohexane]tris(triflate) ............ ${ }^{1} \mathrm{H}: \mathrm{S4}$

${ }^{19} \mathrm{~F}: \mathrm{S4}$

Gadolinium[tetrakis(2-pyridylmethyl)diaminocyclohexane]tris(triflate) ........... ${ }^{1} \mathrm{H}$ : S5

Terbium[tetrakis(2-pyridylmethyl)diaminocyclohexane]tris(triflate)................. ${ }^{1} \mathrm{H}$ : S5

${ }^{19} \mathrm{~F}:$ S6

Dysprosium[tetrakis(2-pyridylmethyl)diaminocyclohexane]tris(triflate) .......... ${ }^{1} \mathrm{H}$ : S6

${ }^{19} \mathrm{~F}: \mathrm{S} 7$

\section{Luminescence}

Photophysical Characterization of samarium complexes ......................................... S7

glum plot of samarium complexes ..................................................................................... S8

Photophysical Characterization of europium complexes................................................ S8

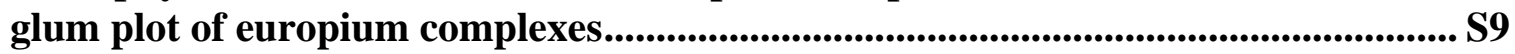

Photophysical Characterization of terbium complexes................................................ S9

glum plot of terbium complexes................................................................................................... S10

Photophysical Characterization of dysprosium complexes....................................... S10

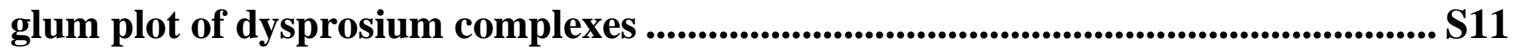

Phosphorescence spectrum of $((\mathrm{S}, \mathrm{S})$-tpdac $) \mathrm{Gd}(\mathrm{OTf})_{3}$ with Deconvolution.............. S11

\section{Lifetime}

Graphic for Lifetime Parameters

Samarium 
Europium

581 nm: S14 594 nm: S14

$614 \mathrm{~nm}$ : S15

649 nm: S15

684 nm: S16

$701 \mathrm{~nm}:$ S16

Terbium

490 nm: S17

545 nm: S17

584 nm: S18

$593 \mathrm{~nm}:$ S18

$623 \mathrm{~nm}$ : S19

645 nm: S19

654 nm: S20

$671 \mathrm{~nm}:$ S20

682 nm: S21

Dysprosium $484 \mathrm{~nm}$ : S21

578 nm: S22

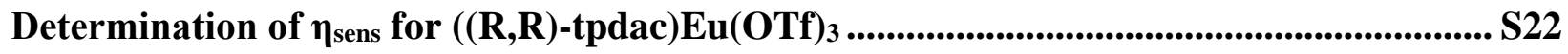

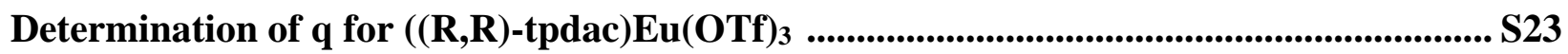

Correction Curves for Duetta Emission ............................................................................................. S24

Uncorrected Spectrum for $\operatorname{Eu}(\mathbf{R}, \mathbf{R})$................................................................................................. S25

Correction Information for the CPL Solo ..................................................................................... S26

Quantum Yield Determination ................................................................................................................. S27

XRD

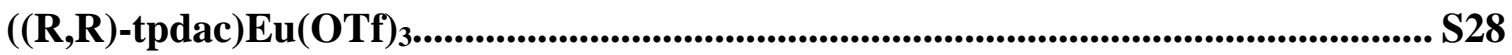

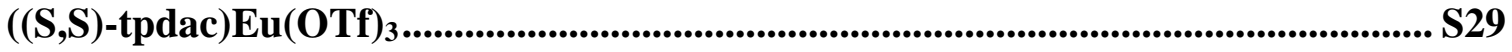

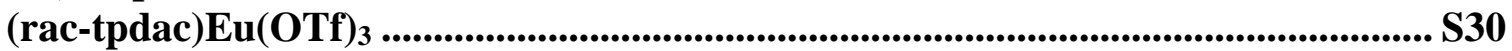

Coordination Geometry about the Metal for Eu Species............................................................ S31

References ....................................................................................................................................... S32 


\section{NMR}

\section{Samarium[(R,R)-tetrakis(2-pyridylmethyl)diaminocyclohexane]tris(triflate)}

${ }^{1} \mathrm{H}(400.144 \mathrm{MHz})$

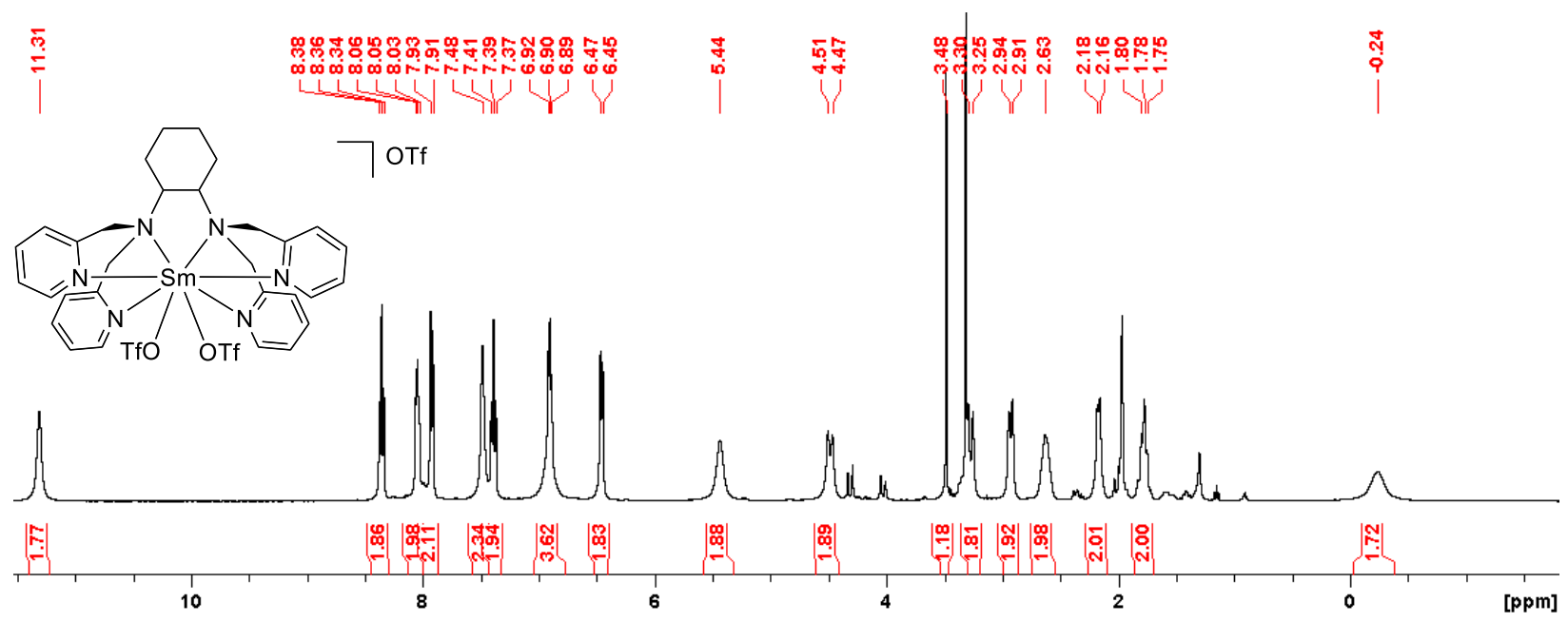

Figure S1: ${ }^{1} \mathrm{H}$ NMR of $(\mathrm{R}, \mathrm{R})$-samarium complex in $\mathrm{ACN}-\mathrm{d}_{3}$. The spectrum for the enantiomer is identical as expected.

${ }^{19} \mathrm{~F}(376.512 \mathrm{MHz})$

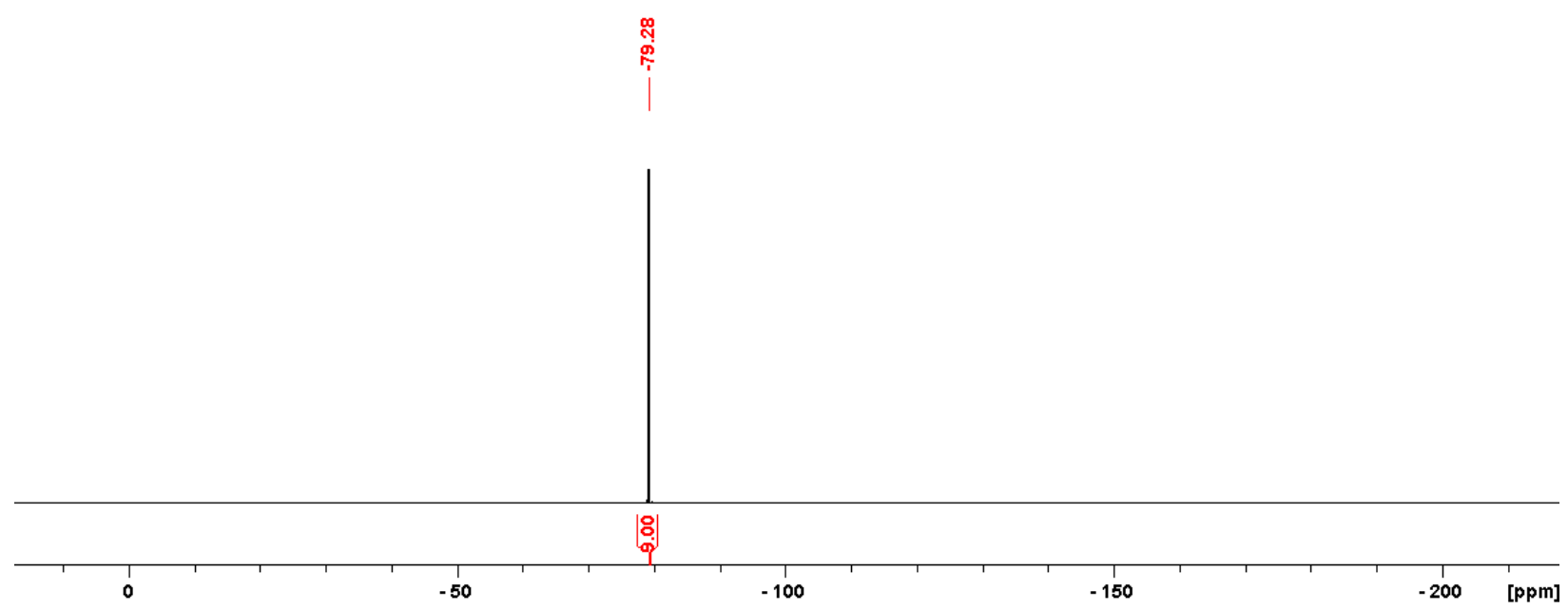

Figure S2: ${ }^{19} \mathrm{~F}$ NMR of $(\mathrm{R}, \mathrm{R})$-samarium complex in $\mathrm{ACN}-\mathrm{d}_{3}$. The spectrum for the enantiomer is identical as expected. 


\section{Europium[(R,R)-tetrakis(2-pyridylmethyl)diaminocyclohexane]tris(triflate)}

${ }^{1} \mathrm{H}(400.144 \mathrm{MHz})$

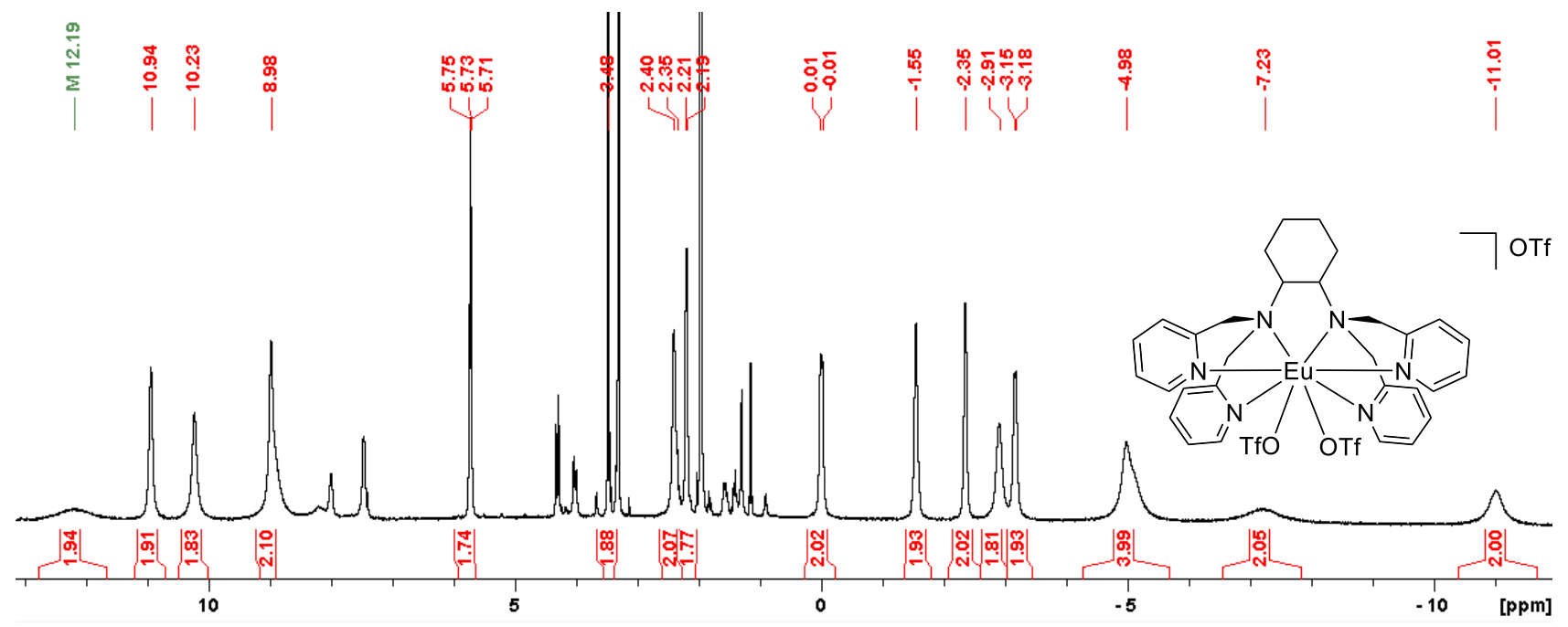

Figure S3: ${ }^{1} \mathrm{H}$ NMR of $(\mathrm{R}, \mathrm{R})$-europium complex NMR in $\mathrm{ACN}-\mathrm{d}_{3}$. The spectrum for the enantiomer is identical as expected.

${ }^{19} \mathrm{~F}(376.512 \mathrm{MHz})$
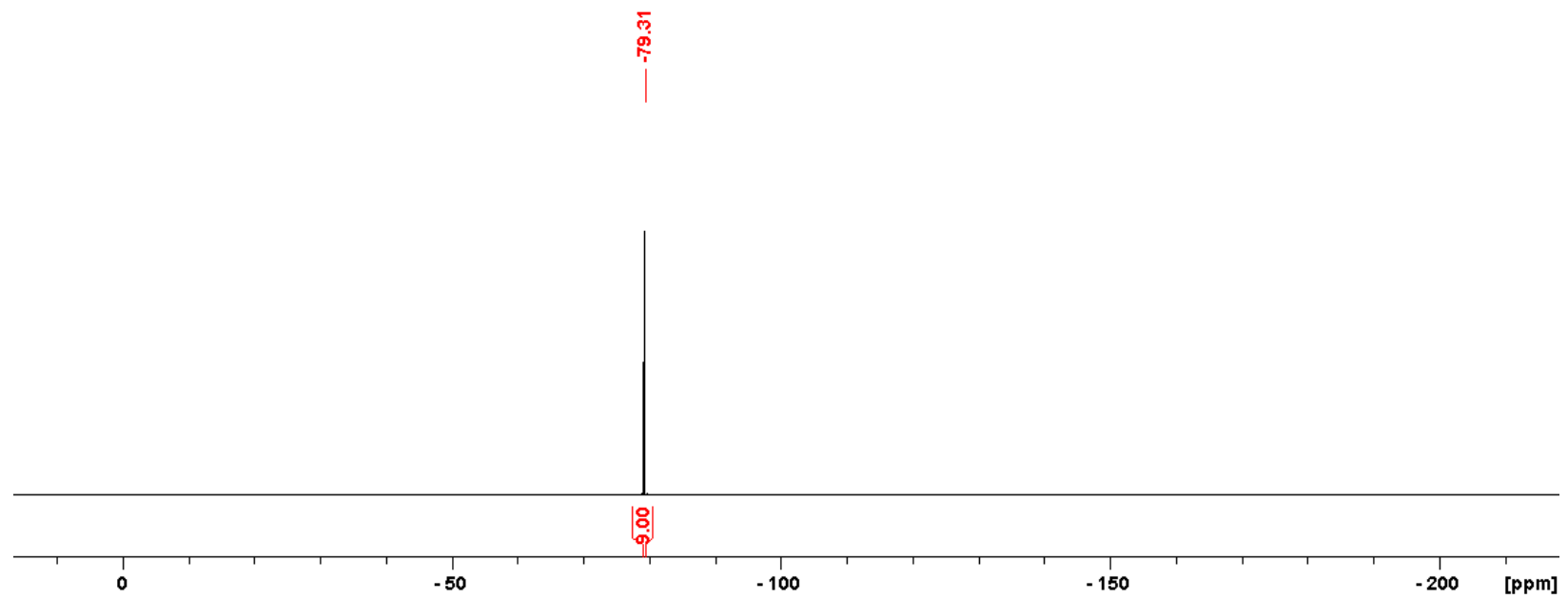

Figure S4: ${ }^{19} \mathrm{~F}$ NMR of $(\mathrm{R}, \mathrm{R})$-europium complex in $\mathrm{ACN}-\mathrm{d}_{3}$. The spectrum for the enantiomer is identical as expected. 


\section{Gadolinium[(S,S)-tetrakis(2-pyridylmethyl)diaminocyclohexane]tris(triflate)}

${ }^{1} \mathrm{H}(400.144 \mathrm{MHz})$

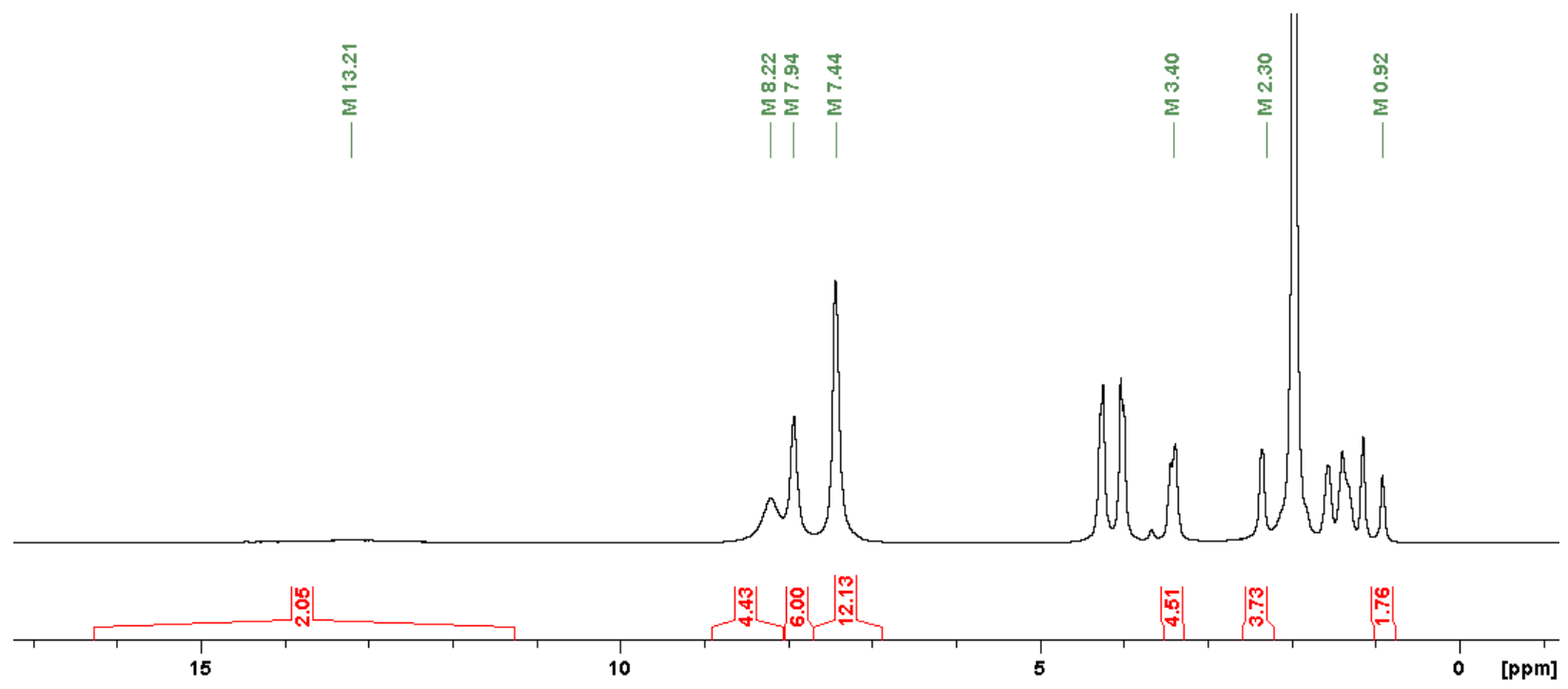

Figure S5: ${ }^{1} \mathrm{H}$ NMR of $(\mathrm{S}, \mathrm{S})$-gadolinium complex in $\mathrm{ACN}-\mathrm{d}_{3}$. The spectrum for the enantiomer is identical as expected.

Terbium[(S,S)-tetrakis(2-pyridylmethyl)diaminocyclohexane]tris(triflate)

${ }^{1} \mathrm{H}(400.144 \mathrm{MHz})$

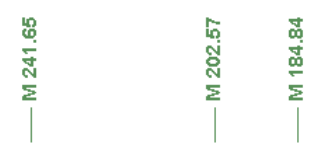
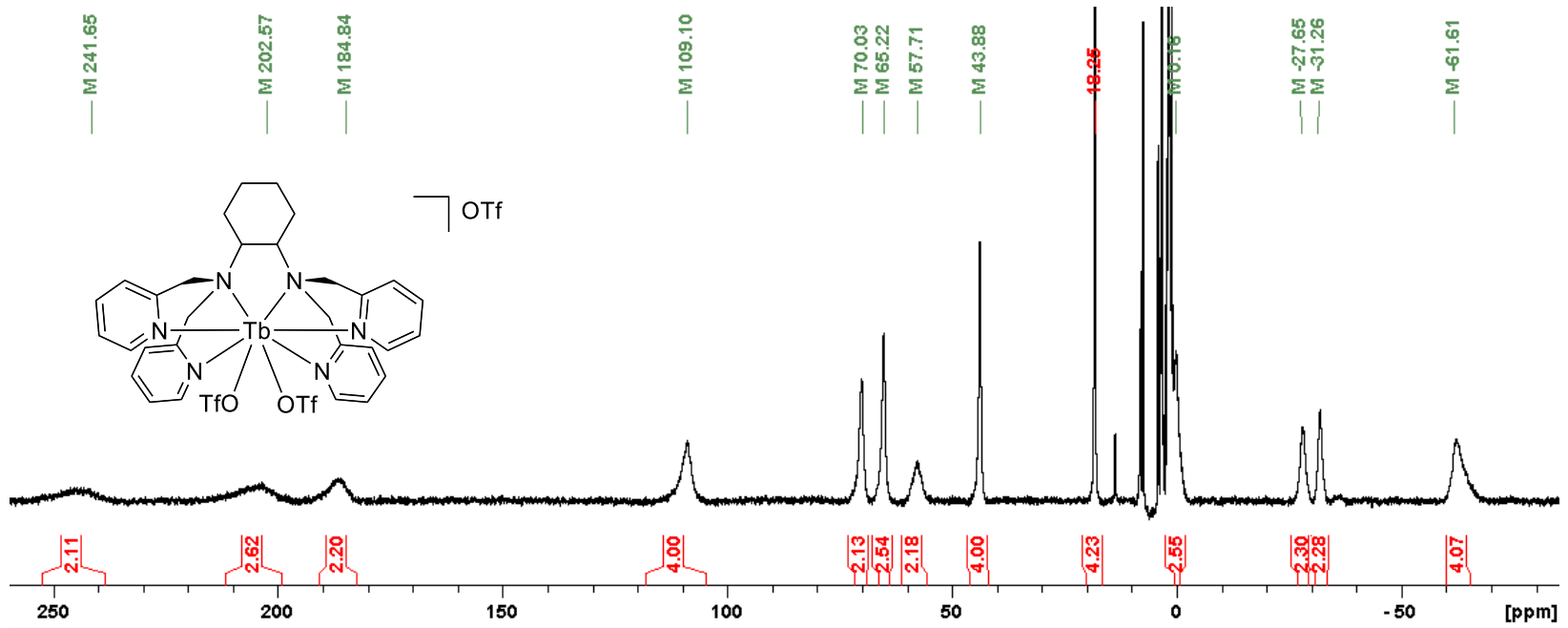

Figure S6: ${ }^{1} \mathrm{H}$ NMR of $(\mathrm{S}, \mathrm{S})$-terbium complex in $\mathrm{ACN}-\mathrm{d}_{3}$. The spectrum for the enantiomer is identical as expected. 


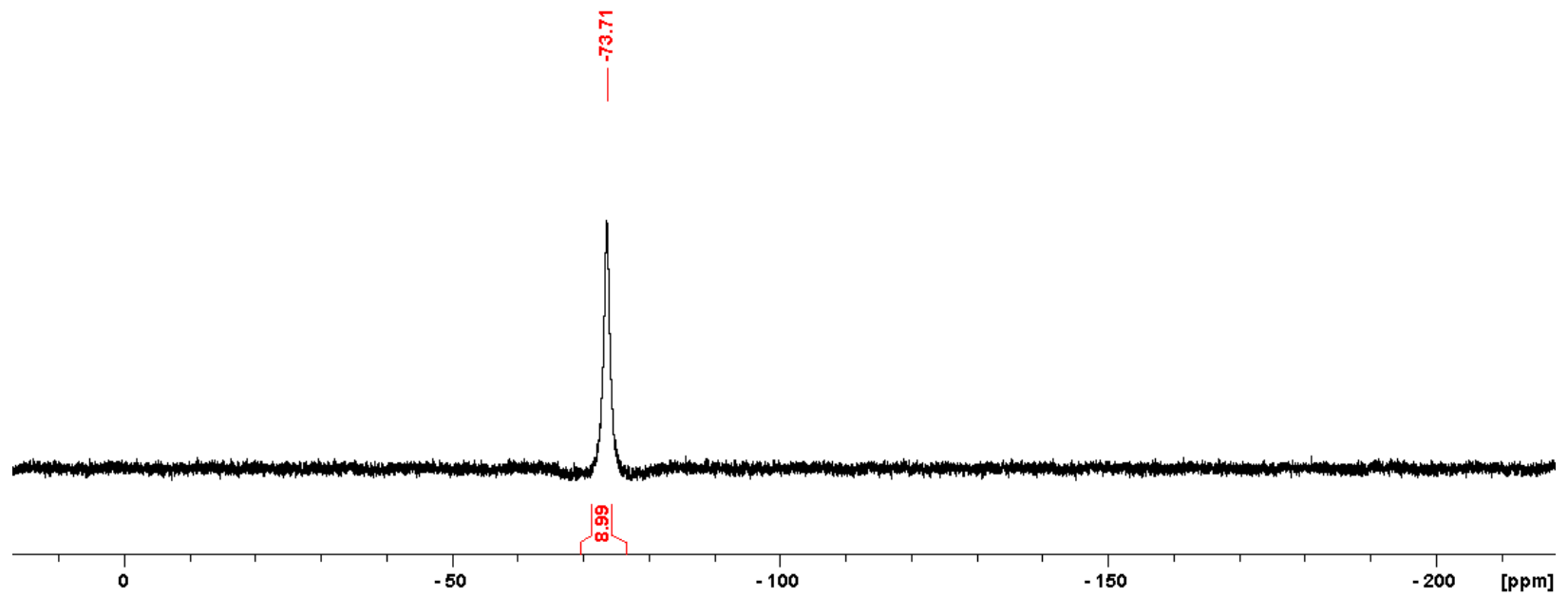

Figure S7: ${ }^{19} \mathrm{~F}$ NMR of $(\mathrm{S}, \mathrm{S})$-terbium complex in $\mathrm{ACN}-\mathrm{d}_{3}$. The spectrum for the enantiomer is identical as expected.

\section{Dysprosium[(S,S)-tetrakis(2-pyridylmethyl)diaminocyclohexane]tris(triflate)}

\section{${ }^{1} \mathrm{H}(400.144 \mathrm{MHz})$}
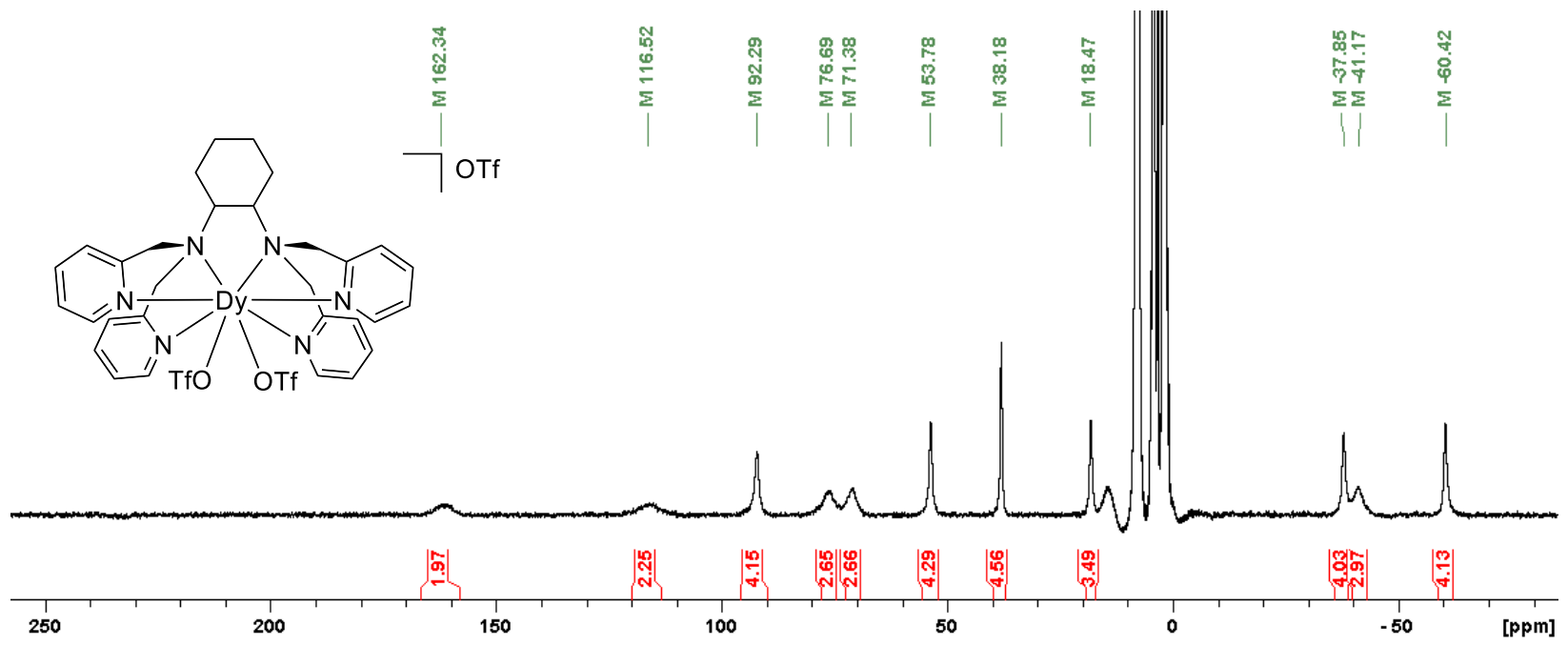

Figure S8: ${ }^{1} \mathrm{H}$ NMR of $(\mathrm{S}, \mathrm{S})$-dysprosium complex in $\mathrm{ACN}-\mathrm{d}_{3}$. The spectrum for the enantiomer is identical as expected. 


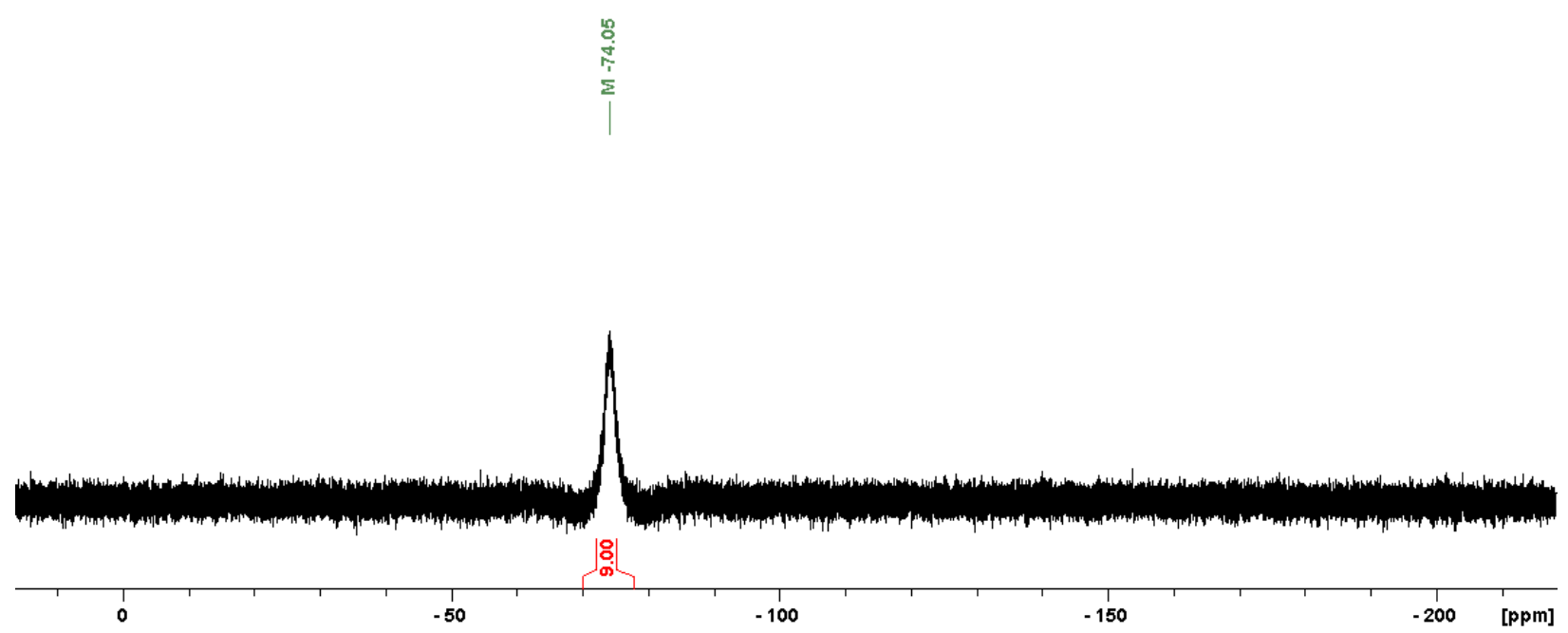

Figure S9: ${ }^{19} \mathrm{~F}$ NMR of (S,S)-dysprosium complex in $\mathrm{ACN}-\mathrm{d}_{3}$. The spectrum for the enantiomer is identical as expected.

\section{$\underline{\text { Luminescence }}$}

\section{$((\mathrm{S}, \mathrm{S})-$ tpdac $) \mathrm{Sm}(\mathrm{OTf})_{3}$}

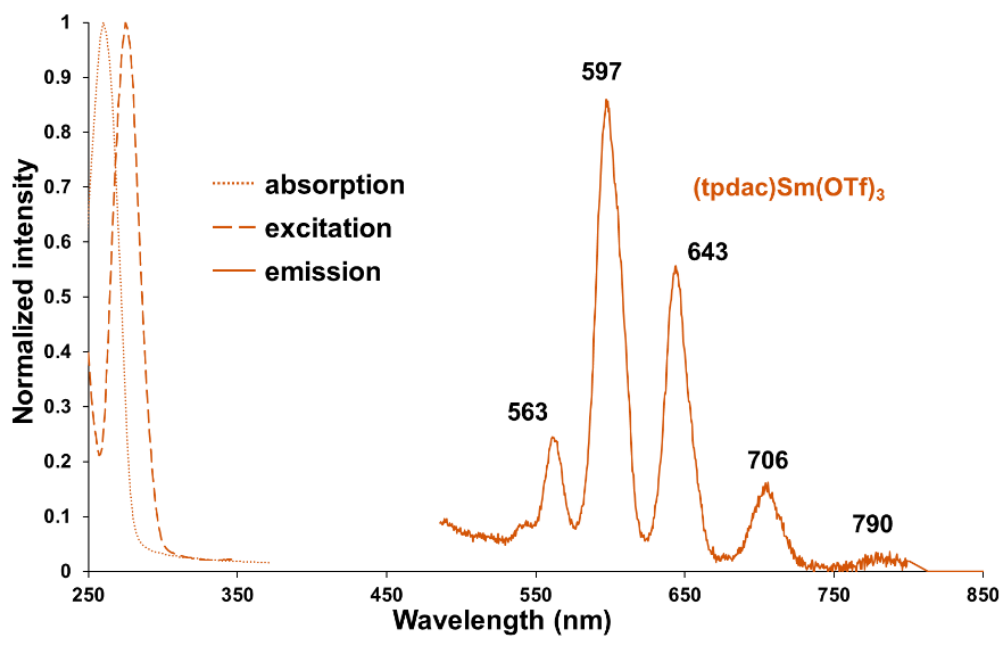

Figure S10: Normalized Absorption (dotted line), Excitation (dashed line) and Emission (solid line) spectra for (S,S)-samarium complex in ACN, $4.6 \times 10^{-6} \mathrm{~mol} \mathrm{~L}^{-1}$. The spectrum for the enantiomer is identical as expected. Slits for absorption $5 \mathrm{~nm}$, for excitation spectra $20 \mathrm{~nm}$ EX and EM, and for emission spectrum $20 \mathrm{~nm}$ EX and $5 \mathrm{~nm}$ EM. 


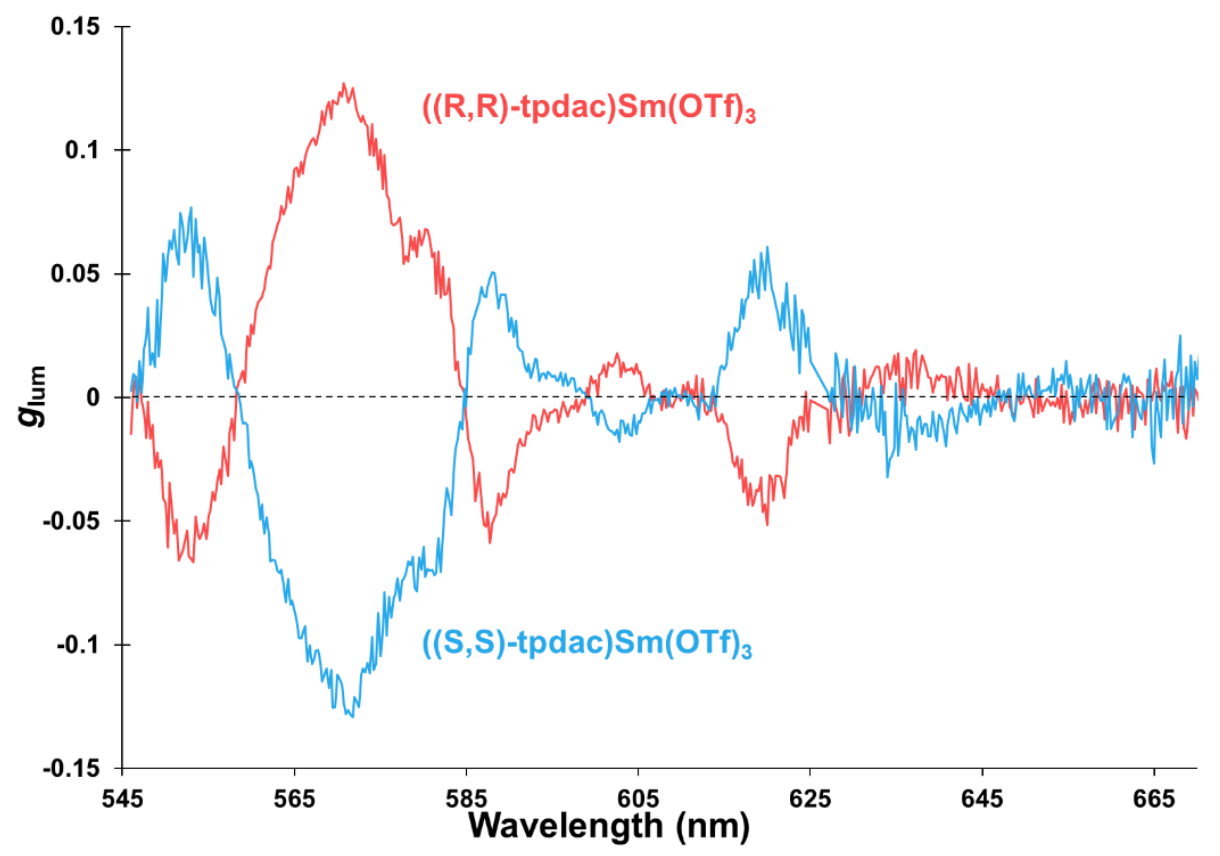

Figure S11: $g_{\text {lum }}$ as a function of wavelength for samarium complexes in ACN at $1.12 \times 10^{-3} \mathrm{~mol} \mathrm{~L}^{-1}$. Slit widths $3.16 \mathrm{~mm}$ EX and EM. Spectrum is taken as an average of 20 scans with $0.25 \mathrm{~nm}$ increments and 5 second integration time.

\section{$((\mathbf{R}, \mathbf{R})-$ tpdac $) \mathbf{E u}(\mathbf{O T f})_{3}$}

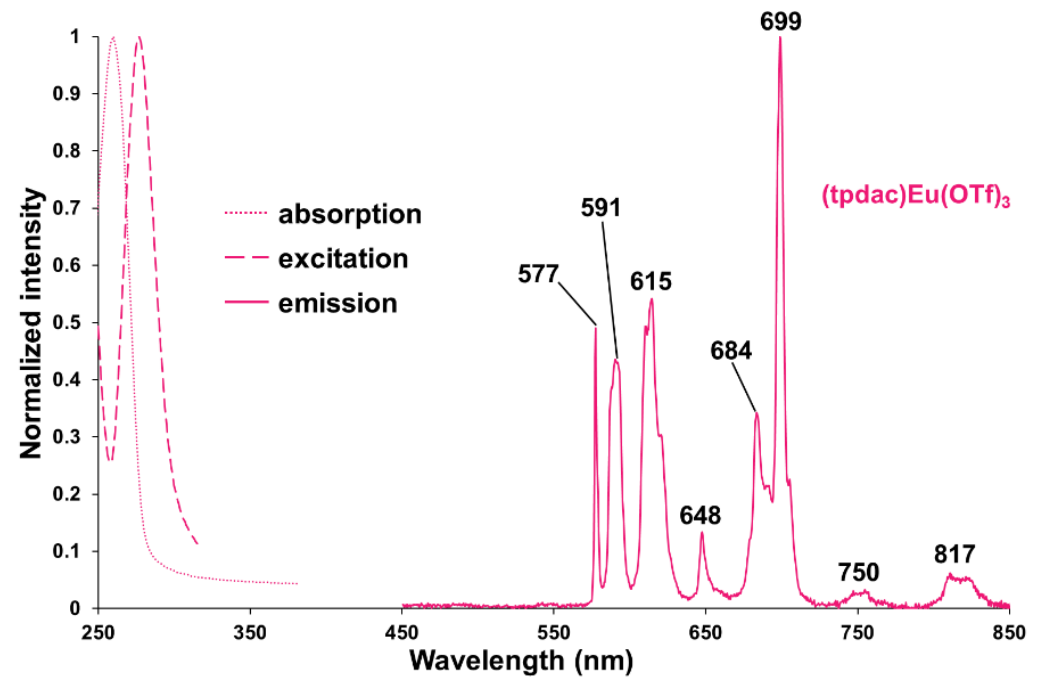

Figure S12: Normalized Absorption (dotted line), Excitation (dashed line) and Emission (solid line) spectra for (R,R)-europium complex in ACN, $4.3 \times 10^{-6} \mathrm{~mol} \mathrm{~L}^{-1}$. The spectrum for the enantiomer is identical as expected. Slits for absorption $5 \mathrm{~nm}$, for excitation spectra $20 \mathrm{~nm}$ EX and EM, and for emission spectrum $20 \mathrm{~nm}$ EX and $1 \mathrm{~nm}$ EM. 


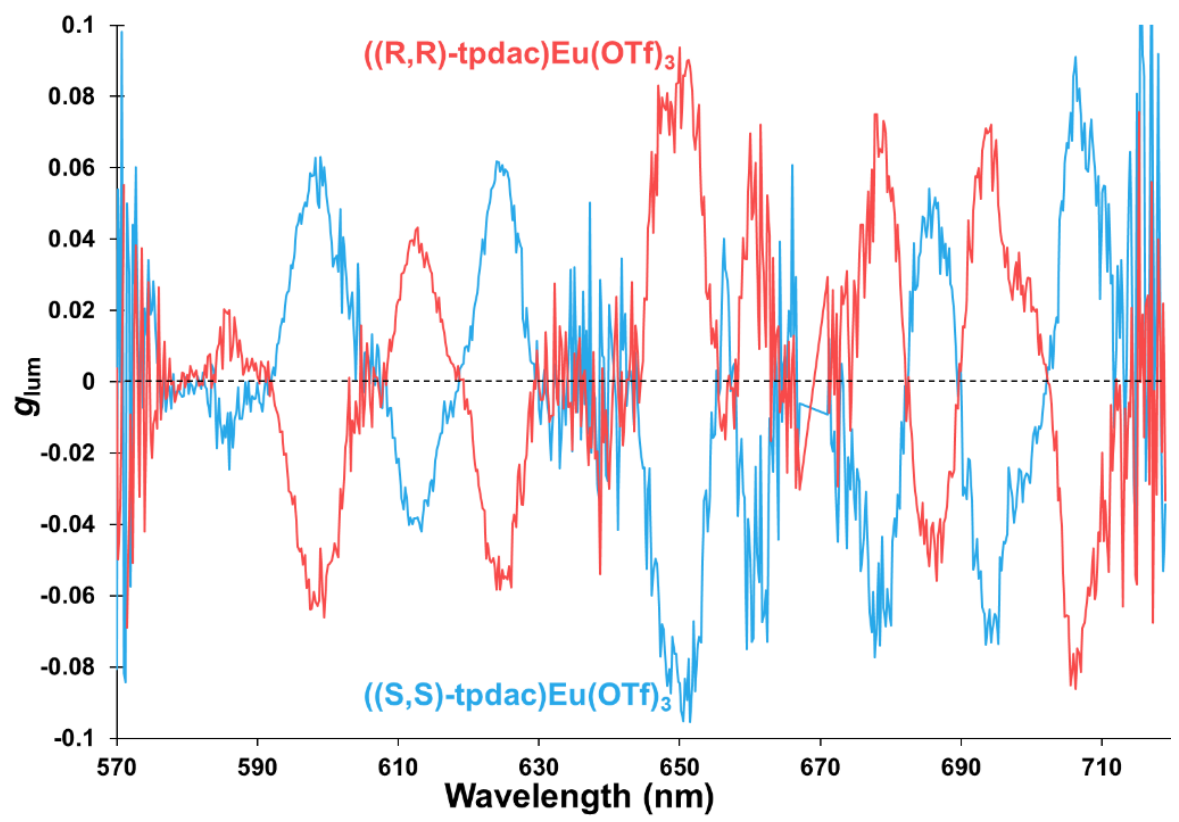

Figure S13: $g_{\text {lum }}$ as a function of wavelength for europium complexes in ACN at $9.27 \times 10^{-4} \mathrm{~mol} \mathrm{~L}^{-1}$. Slit widths $1.24 \mathrm{~mm}$ EX and EM. Spectrum is taken as an average of 25 scans with $0.25 \mathrm{~nm}$ increments and 5 second integration time.

\section{((S,S)-tpdac)Tb(OTf) 3}

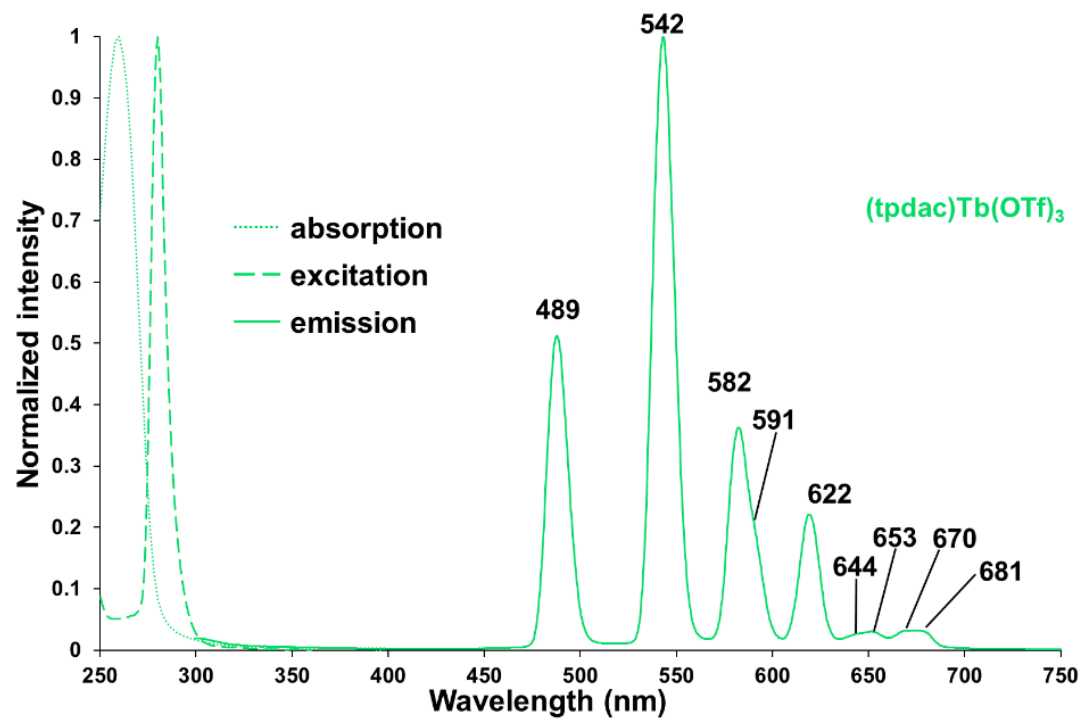

Figure S14: Normalized Absorption (dotted line), Excitation (dashed line) and Emission (solid line) spectra for (S,S)-terbium complex in ACN, $4.7 \times 10^{-6} \mathrm{~mol} \mathrm{~L}^{-1}$. The spectrum for the enantiomer is identical as expected. Slits for absorption $5 \mathrm{~nm}$, for excitation spectra $5 \mathrm{~nm}$ EX and EM, and for emission spectrum $10 \mathrm{~nm}$ EX and $1 \mathrm{~nm}$ EM. 


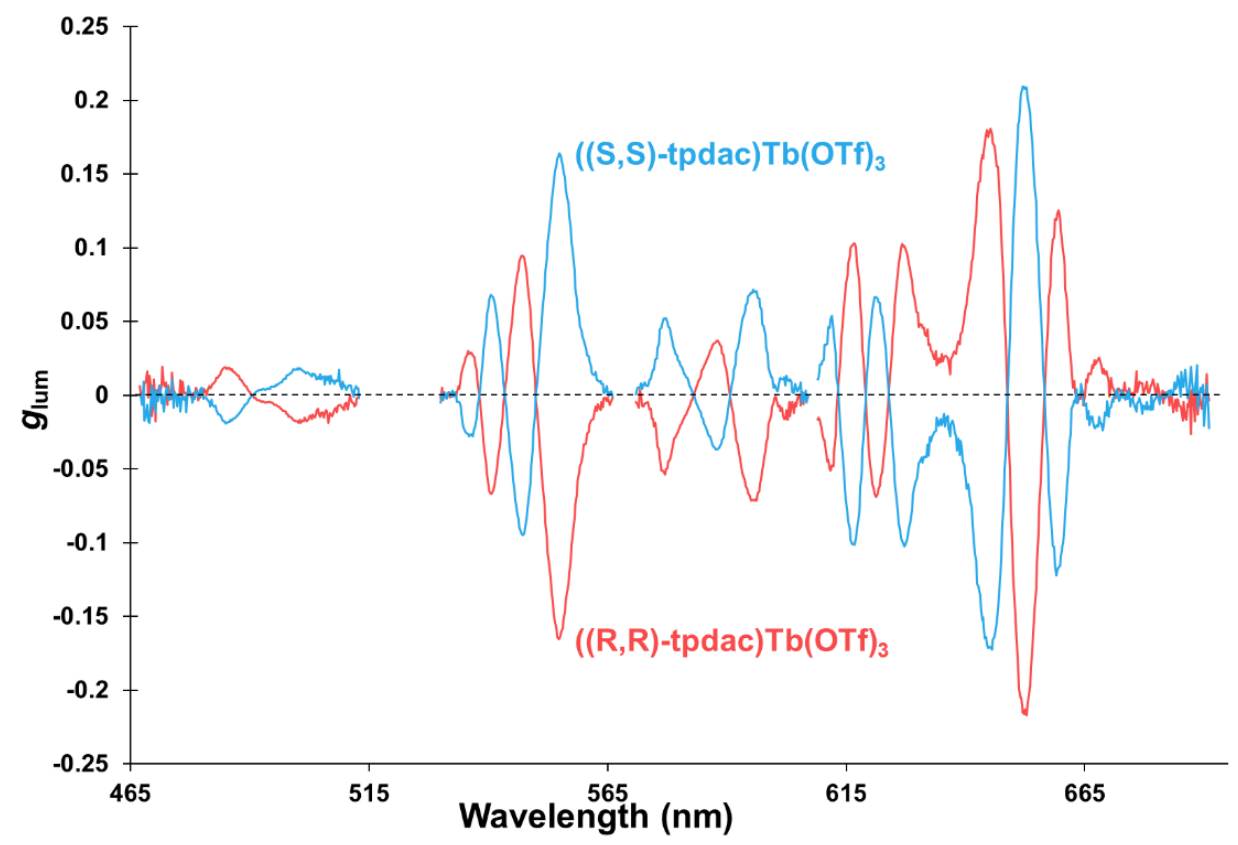

Figure S15: $g_{\text {lum }}$ as a function of wavelength for terbium complexes in ACN at $9.22 \times 10^{-4} \mathrm{~mol} \mathrm{~L}^{-1}$. Slit widths $1.24 \mathrm{~mm}$ EX and EM. Spectrum is taken as an average of 61 scans with $0.25 \mathrm{~nm}$ increments and 1 second integration time.

\section{$((\mathbf{R}, \mathbf{R})$-tpdac $)$ Dy $(\text { OTf })_{3}$}

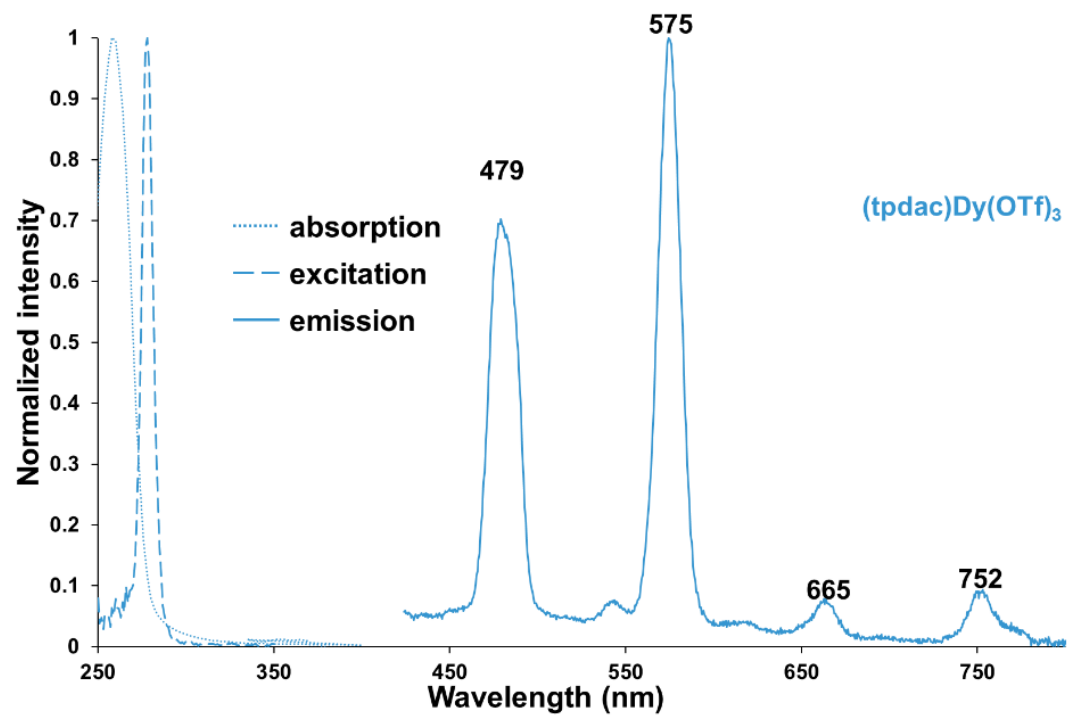

Figure S16: Normalized Absorption (dotted line), Excitation (dashed line) and Emission (solid line) spectra for (R,R)-dysprosium complex in ACN, $4.3 \times 10^{-6} \mathrm{~mol} \mathrm{~L}^{-1}$. The spectrum for the enantiomer is identical as expected. Slits for absorption $5 \mathrm{~nm}$, for excitation spectra $5 \mathrm{~nm}$ EX and EM, and for emission spectrum $20 \mathrm{~nm}$ EX and $10 \mathrm{~nm}$ EM. 


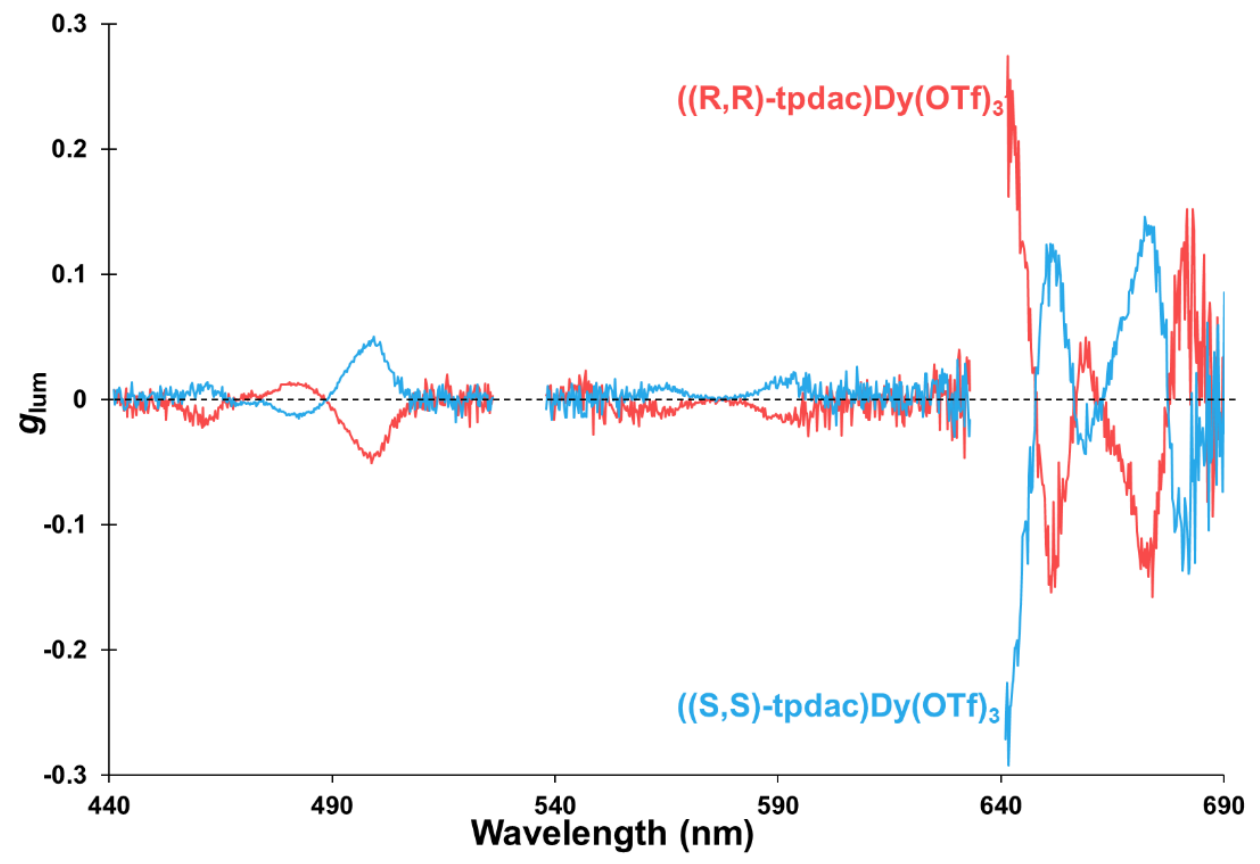

Figure S17: $g_{\text {lum }}$ as a function of wavelength for dysprosium complexes in ACN at $9.19 \times 10^{-4} \mathrm{~mol} \mathrm{~L}^{-1}$. Slit widths $3.16 \mathrm{~mm}$ EX and EM. Spectrum is taken as an average of 16 scans with $0.25 \mathrm{~nm}$ increments and 5 second integration from $441-526 \mathrm{~nm}$ and $538-633 \mathrm{~nm}$ and 10 second integration from $641-695$ $\mathrm{nm}$.

\section{Phosphorescence Spectra $($ S,S-tpdac $)$ Gd $(\text { OTf })_{3}$ with Deconvolution}

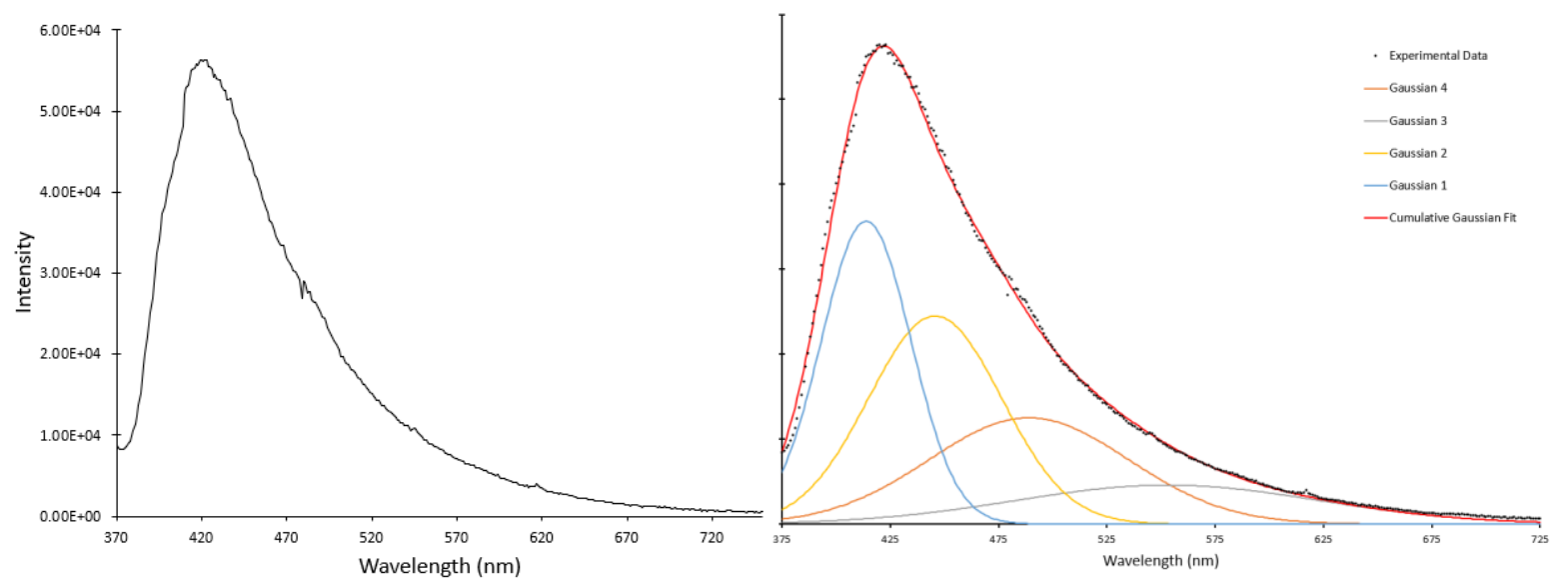

Figure S18: (Left) Phosphorescence spectrum at $77 \mathrm{~K}$ in ACN $9.2 \times 10^{-5} \mathrm{M}$. Slit widths $5 / 0.5 \mathrm{~nm}$ for Ex/Em respectively. (Right) Deconvolution of Gd(tpdac) phosphorescence spectrum into its vibrational progression (Gaussian fit). ${ }^{1}$

\section{$\underline{\text { Lifetime }}$}




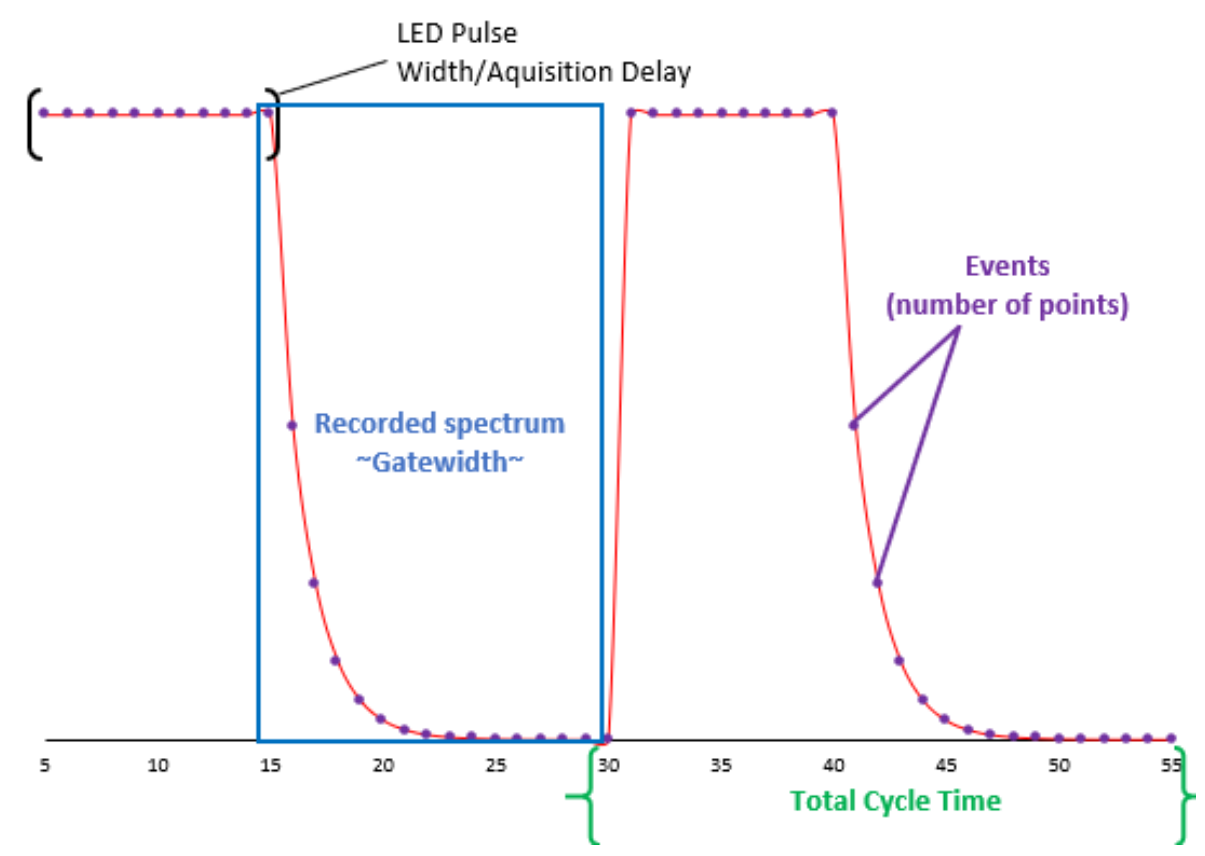

Figure S19: Graphical representation of the lifetime parameters reported below.

\section{$((\mathbf{S}, \mathbf{S})$-tpdac $) \operatorname{Sm}(\mathbf{O T f})_{3}$}
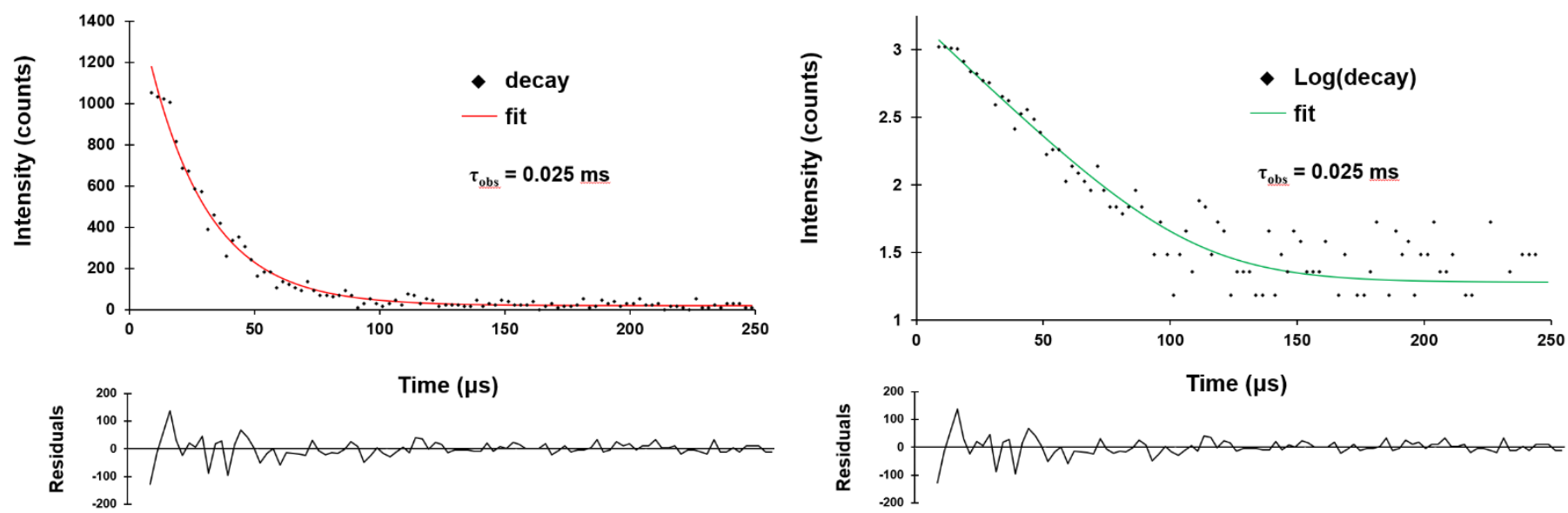

Figure S20: Lifetime exponential (left) and log (right) plots of (S,S)-samarium complex for $595 \mathrm{~nm}$. Excited with $280 \mathrm{~nm}$ LED, with a gate width of 120 (250 $\mu$ s window), $480 \mu$ s delay, $500 \mu$ s LED pulse width, and 1500 events (points) taken over a $1500 \mu$ s total cycle time. Plot is an average of 35 individual runs for better resolution. The lifetime for the enantiomer is identical as expected. 

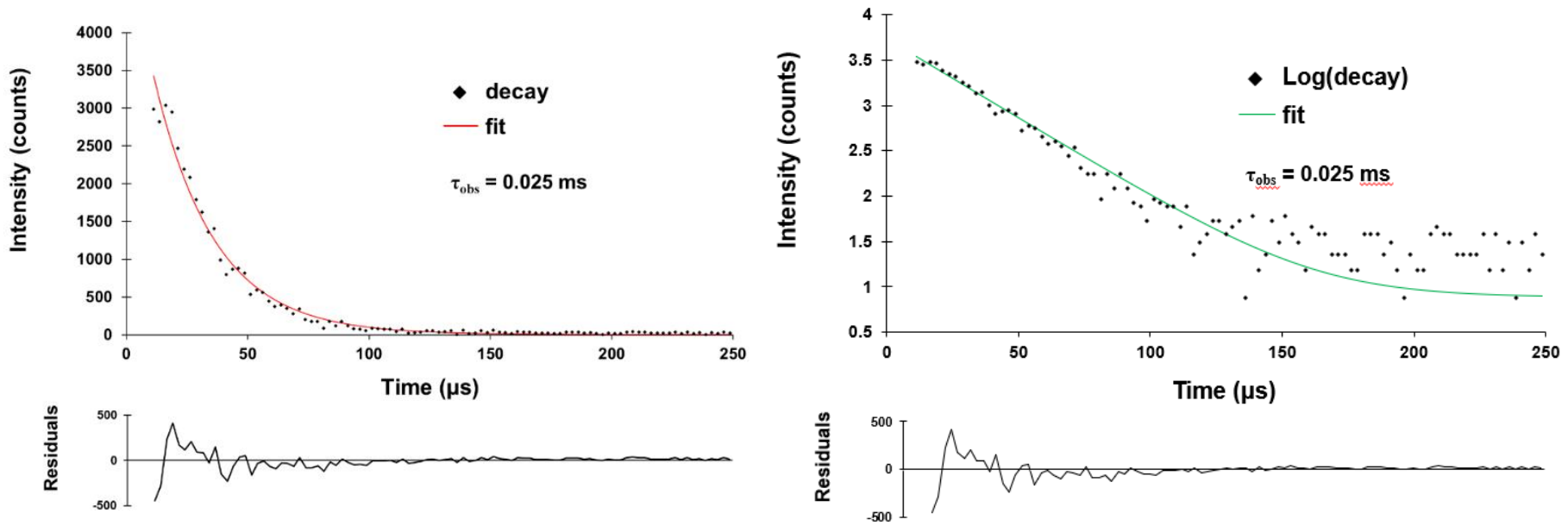

Figure S21: Lifetime exponential (left) and log (right) plots of (S,S)-samarium complex for $601 \mathrm{~nm}$. Excited with $280 \mathrm{~nm}$ LED, with a gate width of 120 (250 $\mu$ s window), $480 \mu$ s delay, $500 \mu$ s LED pulse width, and 1500 events (points) taken over a $1500 \mu$ s total cycle time. Plot is an average of 35 individual runs for better resolution. The lifetime for the enantiomer is identical as expected.
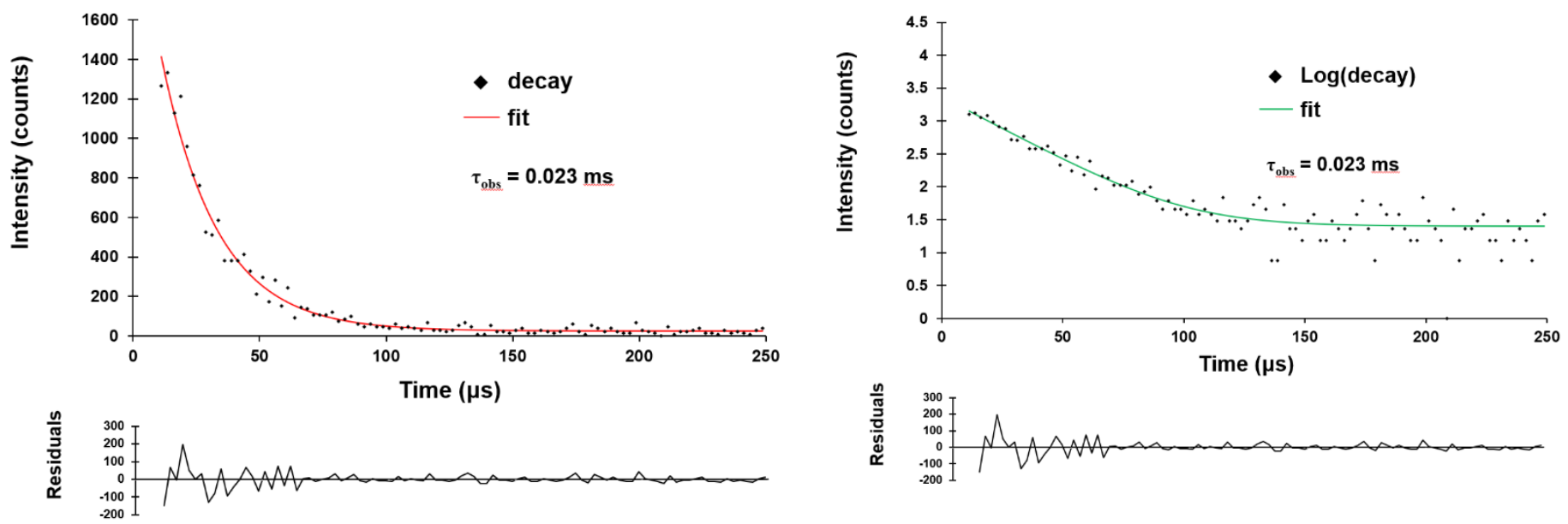

Figure S22: Lifetime exponential (left) and log (right) plots of (S,S)-samarium complex for $646 \mathrm{~nm}$. Excited with $280 \mathrm{~nm}$ LED, with a gate width of 120 (250 $\mu$ s window), $480 \mu$ s delay, $500 \mu$ s LED pulse width, and 1500 events (points) taken over a $1500 \mu$ s total cycle time. Plot is an average of 35 individual runs for better resolution. The lifetime for the enantiomer is identical as expected. 


\section{$\left((\mathbf{R}, \mathbf{R})\right.$-tpdac) $\mathbf{E u}(\mathbf{O T f})_{3}$}
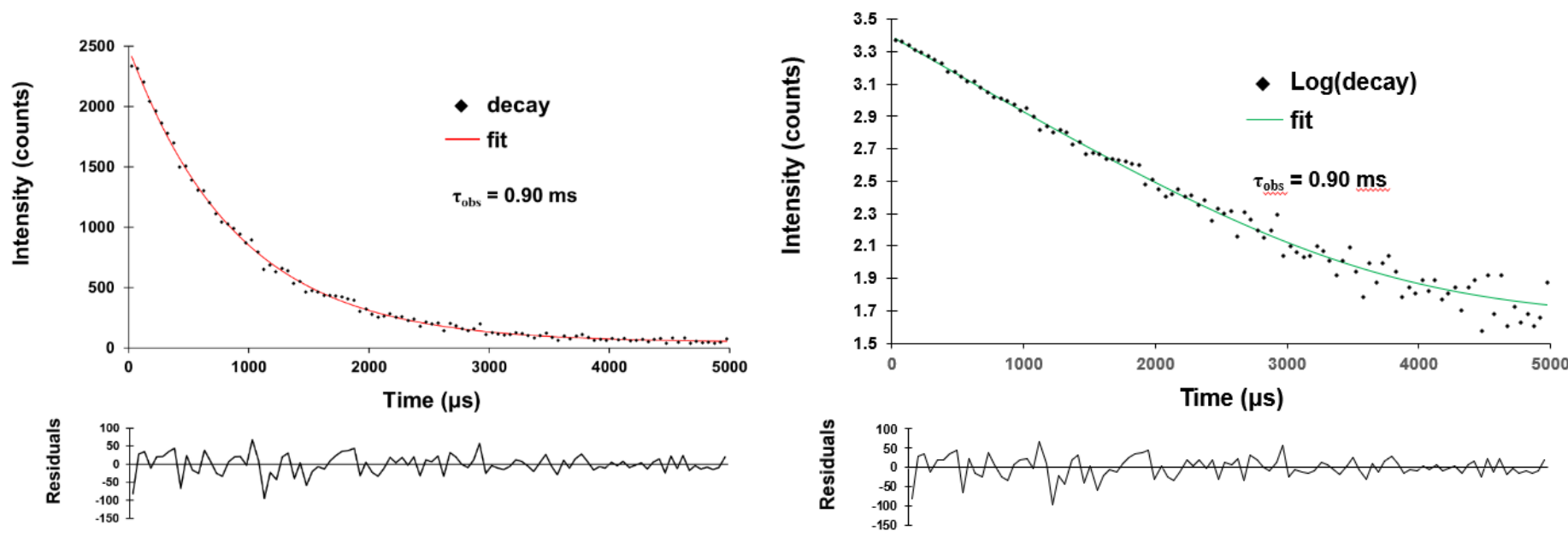

Figure S23: Lifetime exponential (left) and $\log$ (right) plots of (R,R)-europium complex for $581 \mathrm{~nm}$. Excited with $280 \mathrm{~nm} \mathrm{LED}$, with a gate width of 2400 (5000 $\mu$ s window), $1000 \mu$ s delay, $1000 \mu \mathrm{s} \mathrm{LED}$ pulse width, and 300 events (points) taken over a $6000 \mu$ s total cycle time. Plot is an average of 25 individual runs for better resolution. The lifetime for the enantiomer is identical as expected.
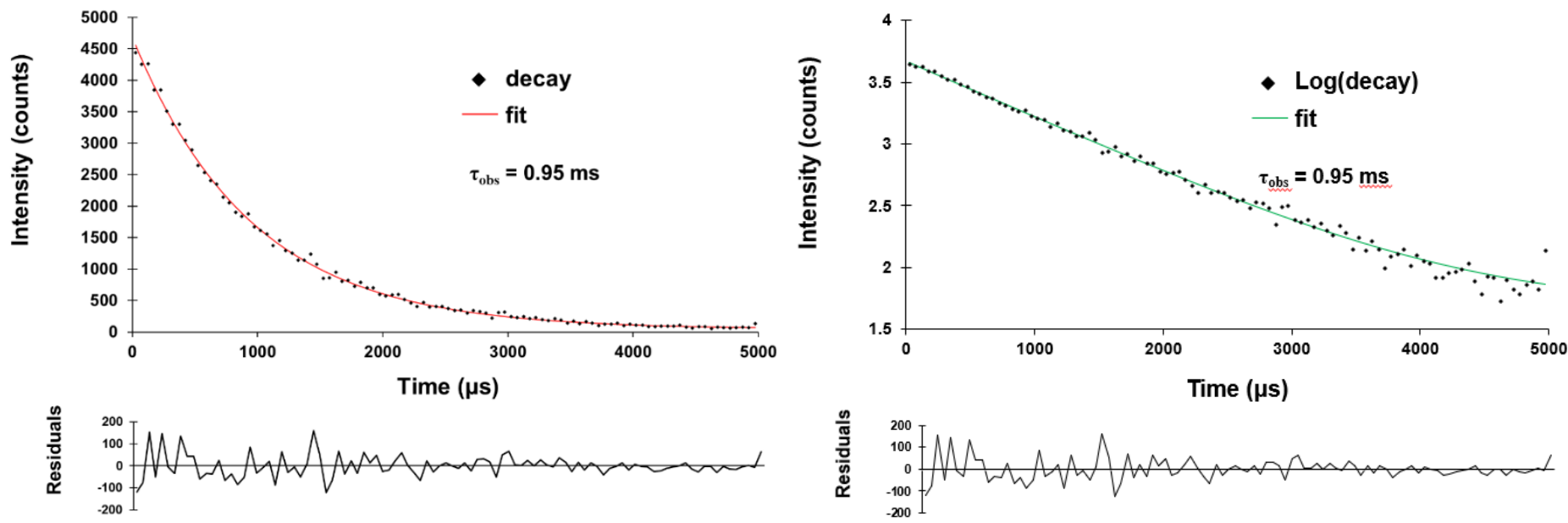

Figure S24: Lifetime exponential (left) and log (right) plots of (R,R)-europium complex for $594 \mathrm{~nm}$. Excited with $280 \mathrm{~nm}$ LED, with a gate width of 2400 (5000 $\mu$ s window), $1000 \mu$ s delay, $1000 \mu \mathrm{s}$ LED pulse width, and 300 events (points) taken over a $6000 \mu$ s total cycle time. Plot is an average of 25 individual runs for better resolution. The lifetime for the enantiomer is identical as expected. 

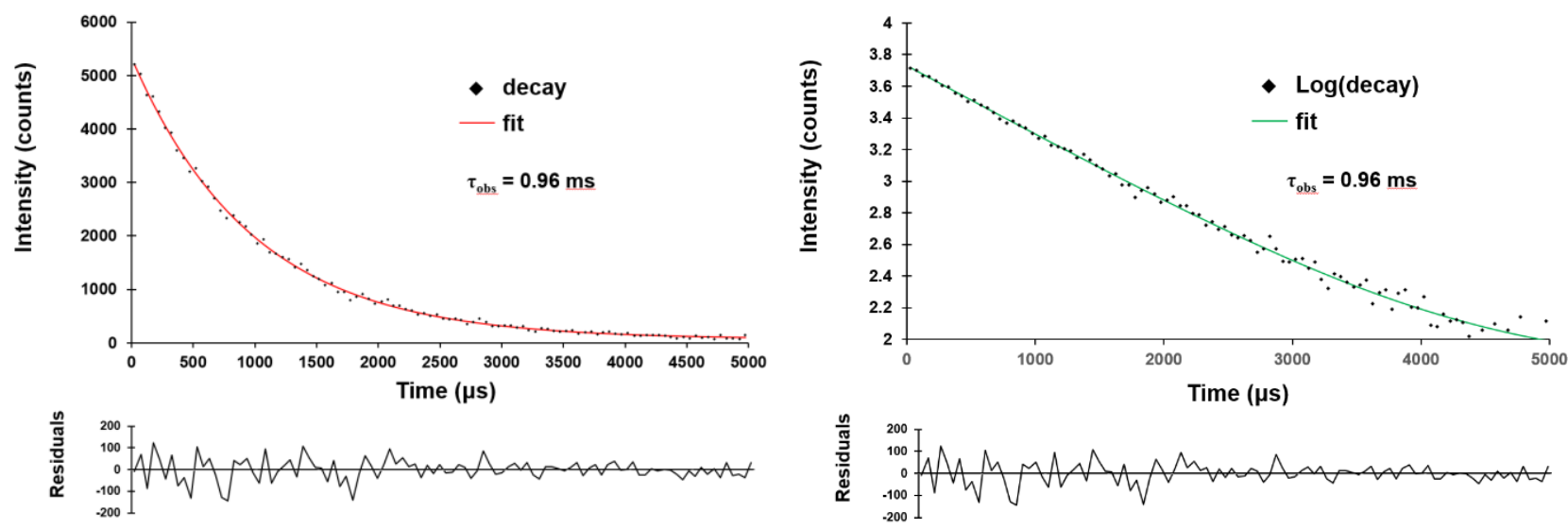

Figure S25: Lifetime exponential (left) and log (right) plots of (R,R)-europium complex for $614 \mathrm{~nm}$. Excited with $280 \mathrm{~nm}$ LED, with a gate width of 2400 (5000 $\mu$ s window), $1000 \mu$ s delay, $1000 \mu \mathrm{s}$ LED pulse width, and 300 events (points) taken over a $6000 \mu$ s total cycle time. Plot is an average of 25 individual runs for better resolution. The lifetime for the enantiomer is identical as expected.
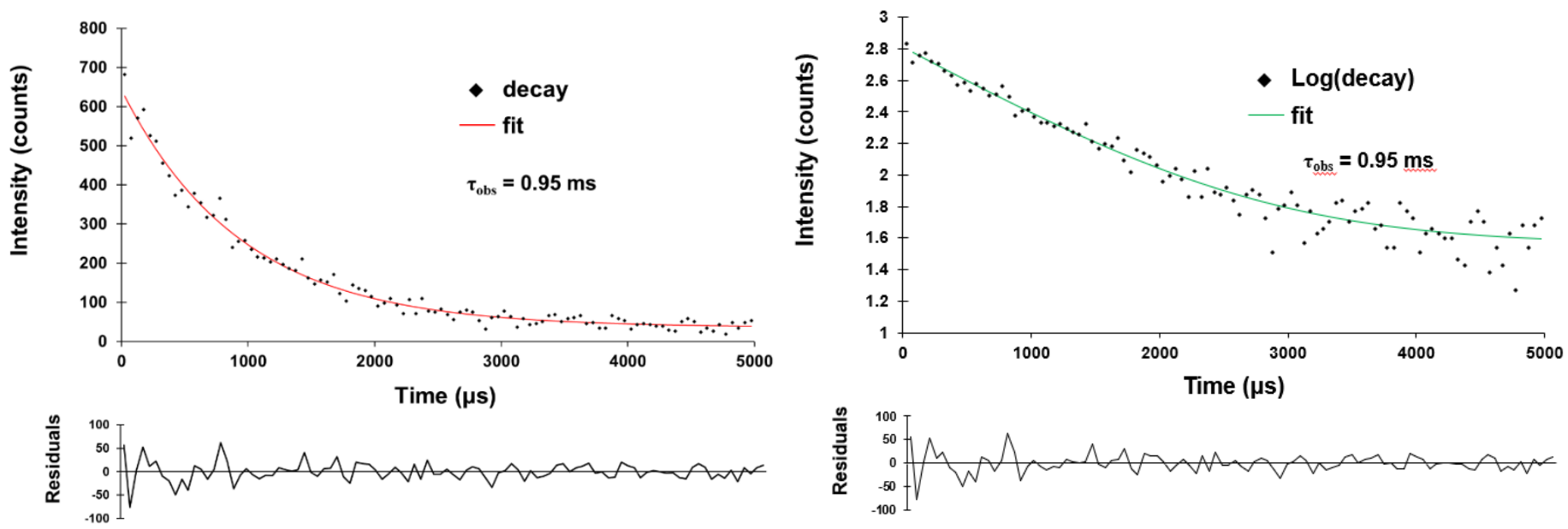

Figure S26: Lifetime exponential (left) and log (right) plots of (R,R)-europium complex for $649 \mathrm{~nm}$. Excited with $280 \mathrm{~nm}$ LED, with a gate width of 2400 (5000 $\mu$ s window), $1000 \mu$ s delay, $1000 \mu$ s LED pulse width, and 300 events (points) taken over a $6000 \mu$ s total cycle time. Plot is an average of 25 individual runs for better resolution. The lifetime for the enantiomer is identical as expected. 

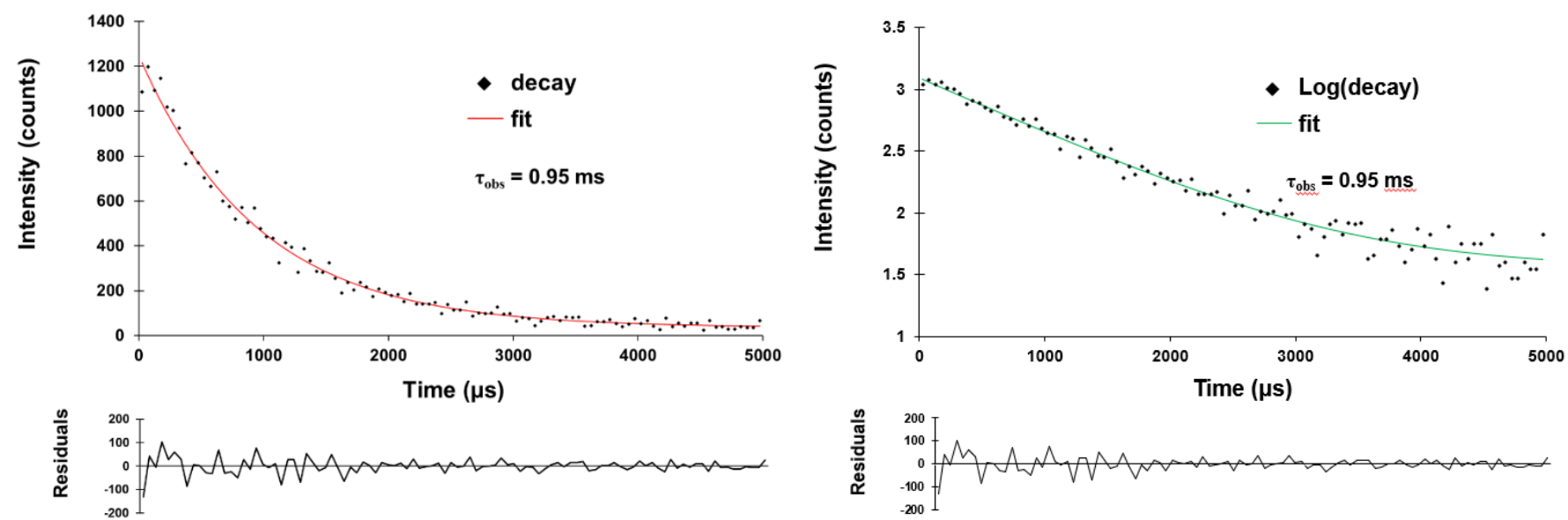

Figure S27: Lifetime exponential (left) and $\log$ (right) plots of (R,R)-europium complex for $684 \mathrm{~nm}$. Excited with $280 \mathrm{~nm}$ LED, with a gate width of 2400 (5000 $\mu$ s window), $1000 \mu$ s delay, $1000 \mu \mathrm{s}$ LED pulse width, and 300 events (points) taken over a $6000 \mu$ s total cycle time. Plot is an average of 25 individual runs for better resolution. The lifetime for the enantiomer is identical as expected.
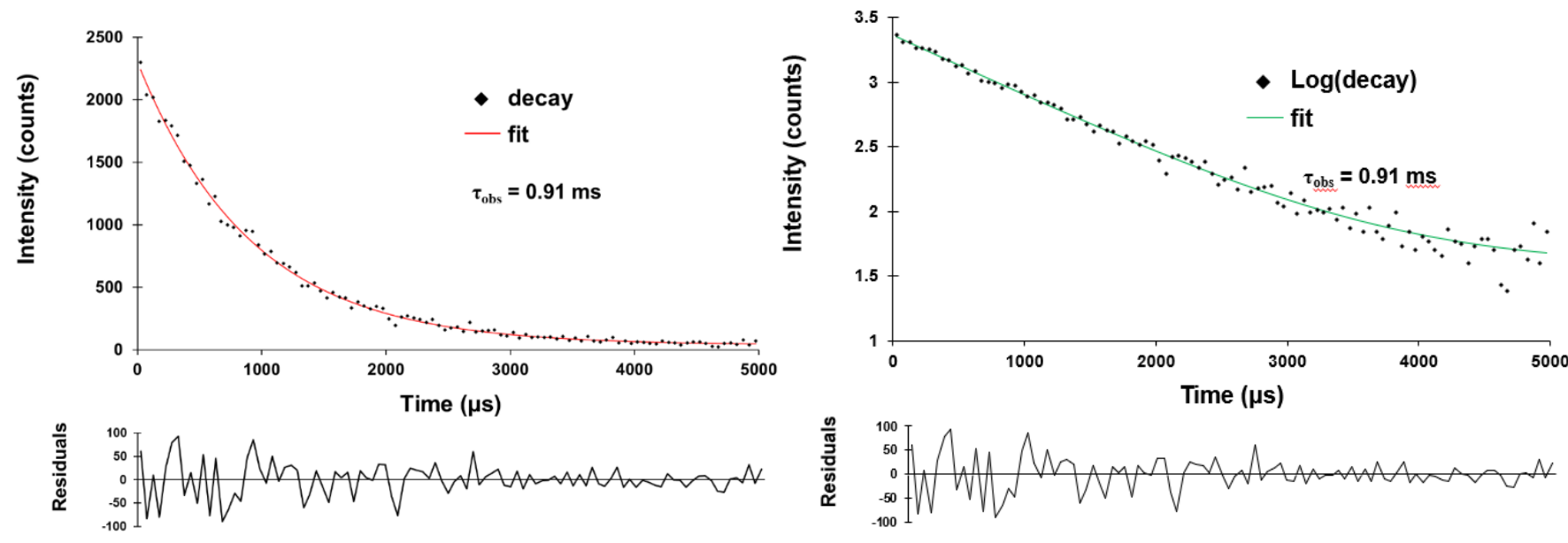

Figure S28: Lifetime exponential (left) and $\log$ (right) plots of (R,R)-europium complex for $701 \mathrm{~nm}$. Excited with $280 \mathrm{~nm}$ LED, with a gate width of 2400 (5000 $\mu$ s window), $1000 \mu$ s delay, $1000 \mu$ s LED pulse width, and 300 events (points) taken over a $6000 \mu$ s total cycle time. Plot is an average of 25 individual runs for better resolution. The lifetime for the enantiomer is identical as expected. 


\section{$((\mathbf{S}, \mathbf{S})$-tpdac) $) \mathbf{T b}(\mathbf{O T f})_{3}$}
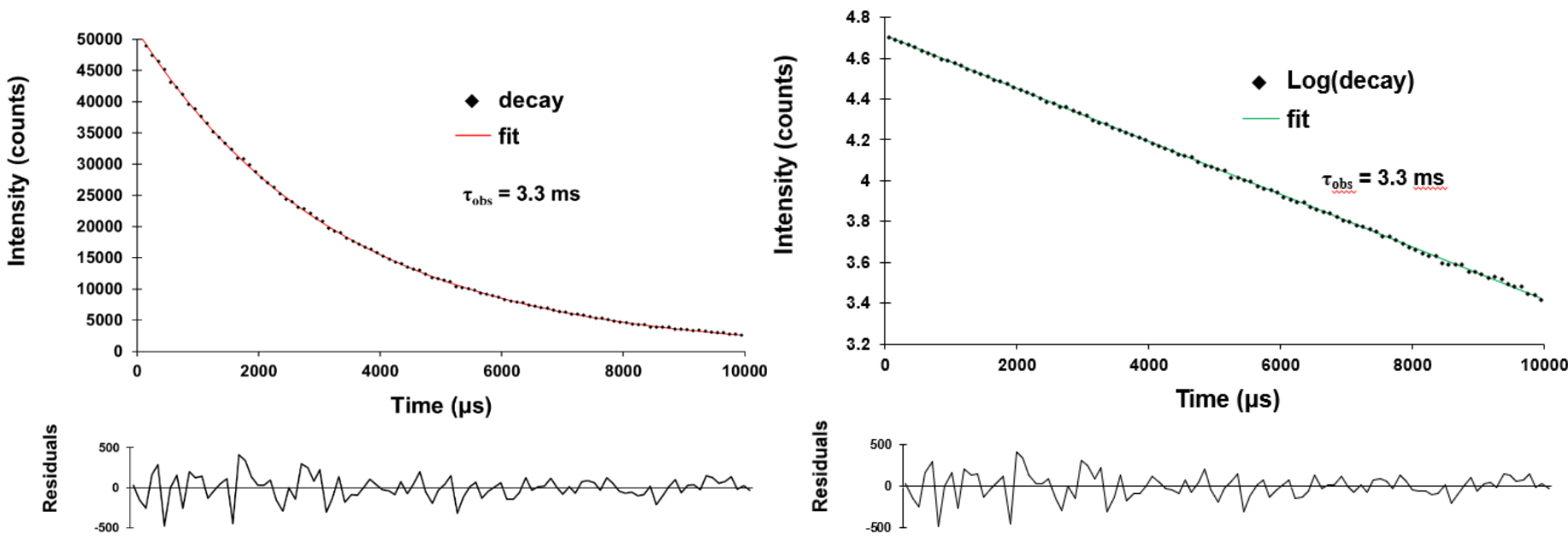

Figure S29: Lifetime exponential (left) and log (right) plots of (S,S)-terbium complex for $490 \mathrm{~nm}$. Excited with $280 \mathrm{~nm}$ LED, with a gate width of 4800 (10000 $\mu$ s window), $550 \mu$ s delay, $600 \mu \mathrm{s}$ LED pulse width, and 300 events (points) taken over a $10500 \mu$ s total cycle time. Plot is an average of 25 individual runs for better resolution. The lifetime for the enantiomer is identical as expected.
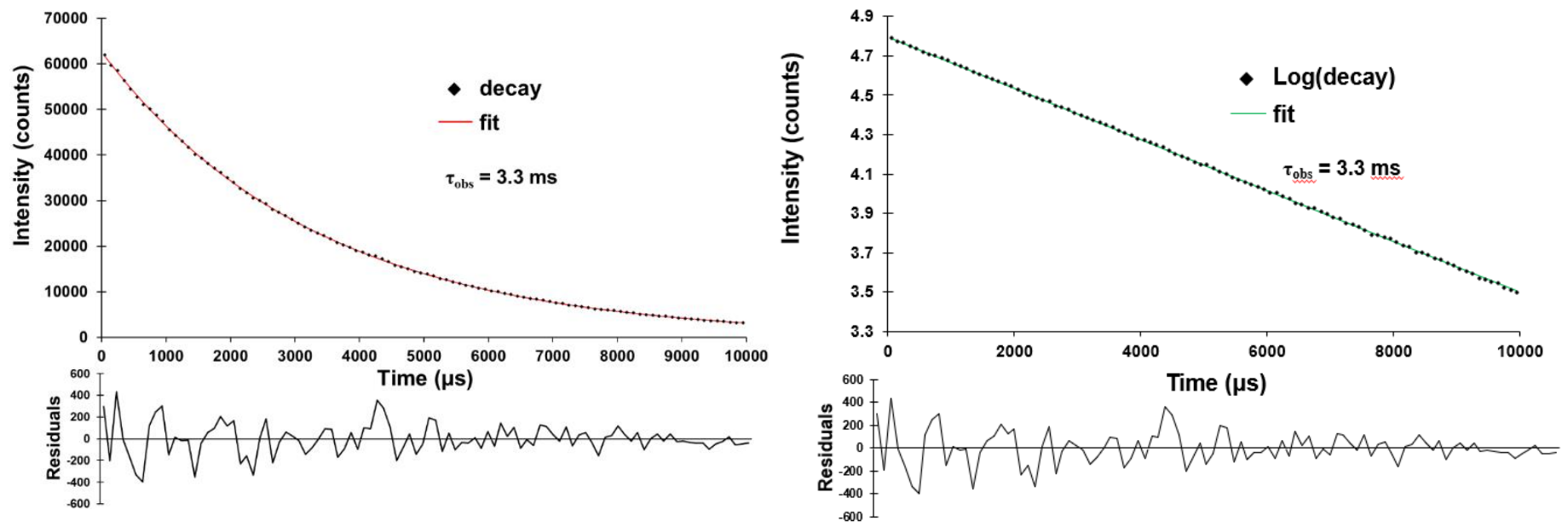

Figure S30: Lifetime exponential (left) and log (right) plots of (S,S)-terbium complex for $545 \mathrm{~nm}$. Excited with $280 \mathrm{~nm}$ LED, with a gate width of 4800 (10000 $\mu$ s window), $550 \mu$ s delay, $600 \mu \mathrm{s} \mathrm{LED}$ pulse width, and 300 events (points) taken over a $10500 \mu$ s total cycle time. Plot is an average of 25 individual runs for better resolution. The lifetime for the enantiomer is identical as expected. 

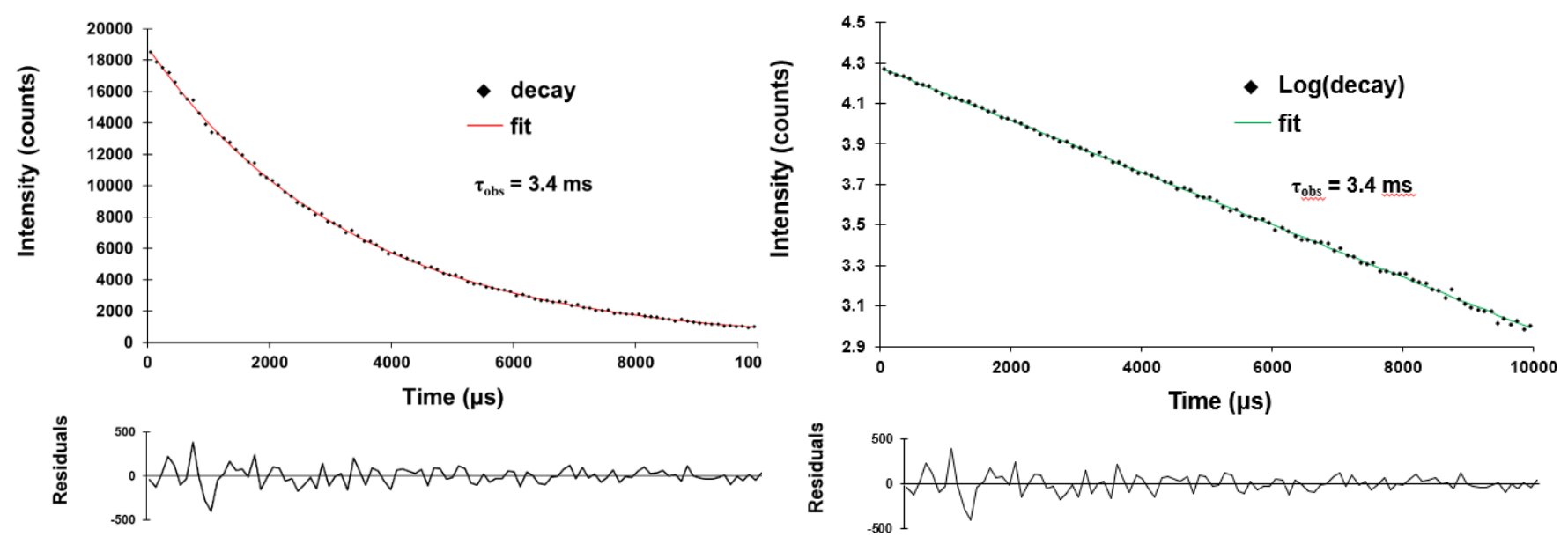

Figure S31: Lifetime exponential (left) and log (right) plots of (S,S)-terbium complex for $584 \mathrm{~nm}$. Excited with $280 \mathrm{~nm}$ LED, with a gate width of 4800 (10000 $\mu$ s window), $550 \mu$ s delay, $600 \mu$ s LED pulse width, and 300 events (points) taken over a $10500 \mu$ s total cycle time. Plot is an average of 25 individual runs for better resolution. The lifetime for the enantiomer is identical as expected.
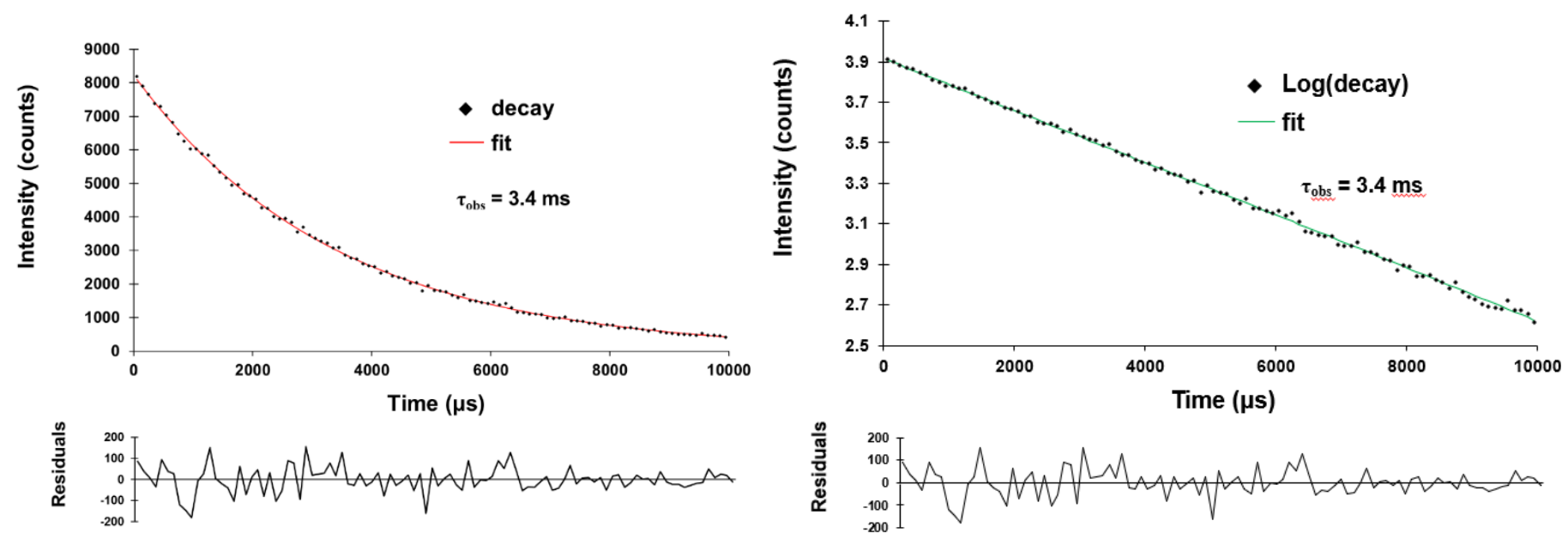

Figure S32: Lifetime exponential (left) and log (right) plots of (S,S)-terbium complex for $593 \mathrm{~nm}$. Excited with $280 \mathrm{~nm}$ LED, with a gate width of 4800 (10000 $\mu$ s window), $550 \mu$ s delay, $600 \mu$ s LED pulse width, and 300 events (points) taken over a $10500 \mu$ s total cycle time. Plot is an average of 25 individual runs for better resolution. The lifetime for the enantiomer is identical as expected. 

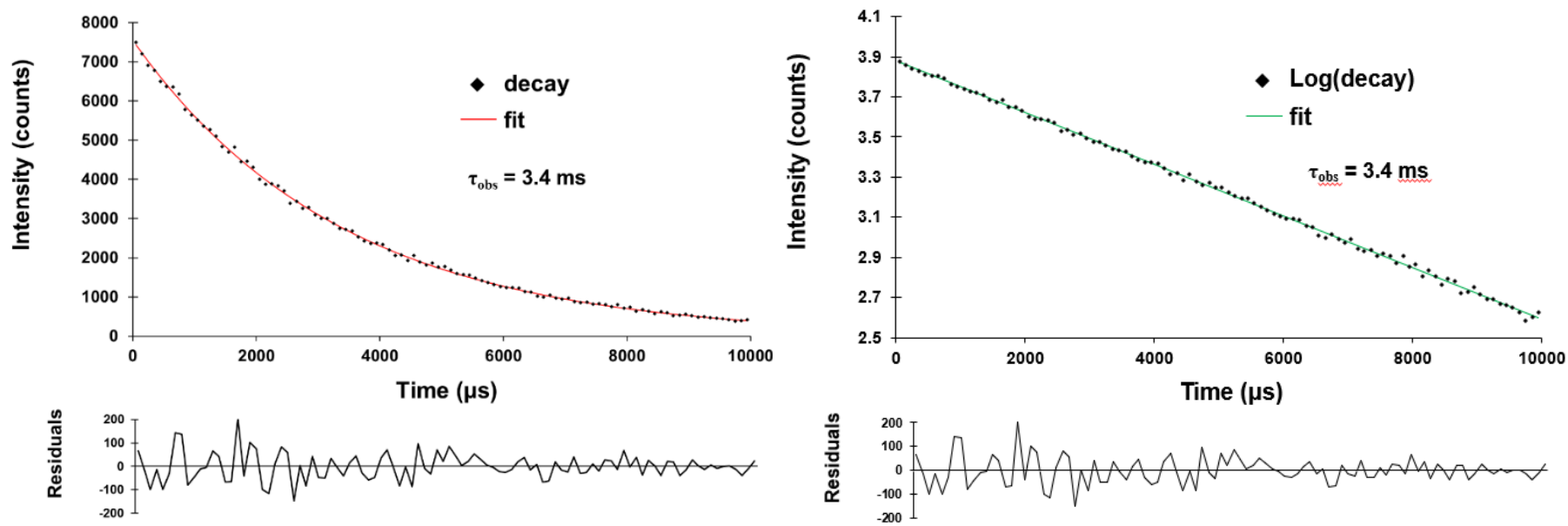

Figure S33: Lifetime exponential (left) and log (right) plots of (S,S)-terbium complex for $623 \mathrm{~nm}$. Excited with $280 \mathrm{~nm}$ LED, with a gate width of 4800 (10000 $\mu$ s window), $550 \mu$ s delay, $600 \mu \mathrm{s} \mathrm{LED}$ pulse width, and 300 events (points) taken over a $10500 \mu$ s total cycle time. Plot is an average of 25 individual runs for better resolution. The lifetime for the enantiomer is identical as expected.
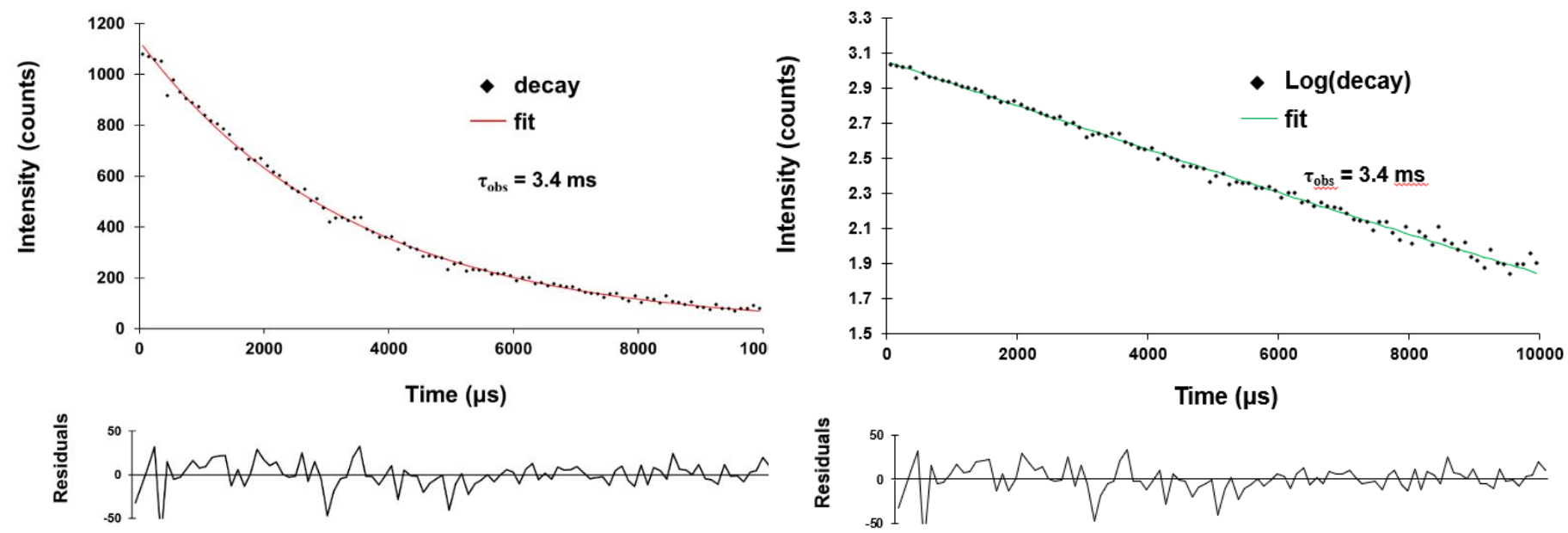

Figure S34: Lifetime exponential (left) and log (right) plots of (S,S)-terbium complex for $645 \mathrm{~nm}$. Excited with $280 \mathrm{~nm}$ LED, with a gate width of 4800 (10000 $\mu$ s window), $1450 \mu$ s delay, $1500 \mu$ s LED pulse width, and 500 events (points) taken over a $11500 \mu$ s total cycle time. Plot is an average of 30 individual runs for better resolution. The lifetime for the enantiomer is identical as expected. 

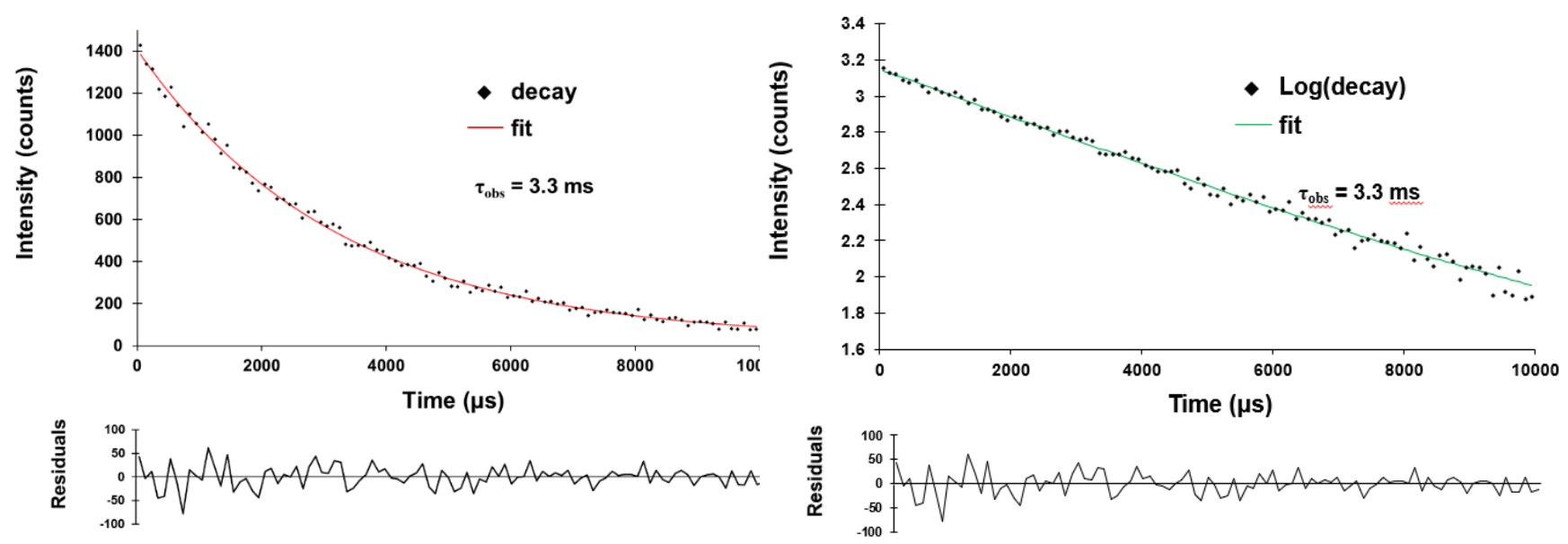

Figure S35: Lifetime exponential (left) and log (right) plots of (S,S)-terbium complex for $654 \mathrm{~nm}$. Excited with $280 \mathrm{~nm}$ LED, with a gate width of 4800 (10000 $\mu$ s window), $1450 \mu$ s delay, $1500 \mu$ s LED pulse width, and 300 events (points) taken over a $11500 \mu$ s total cycle time. Plot is an average of 30 individual runs for better resolution. The lifetime for the enantiomer is identical as expected.
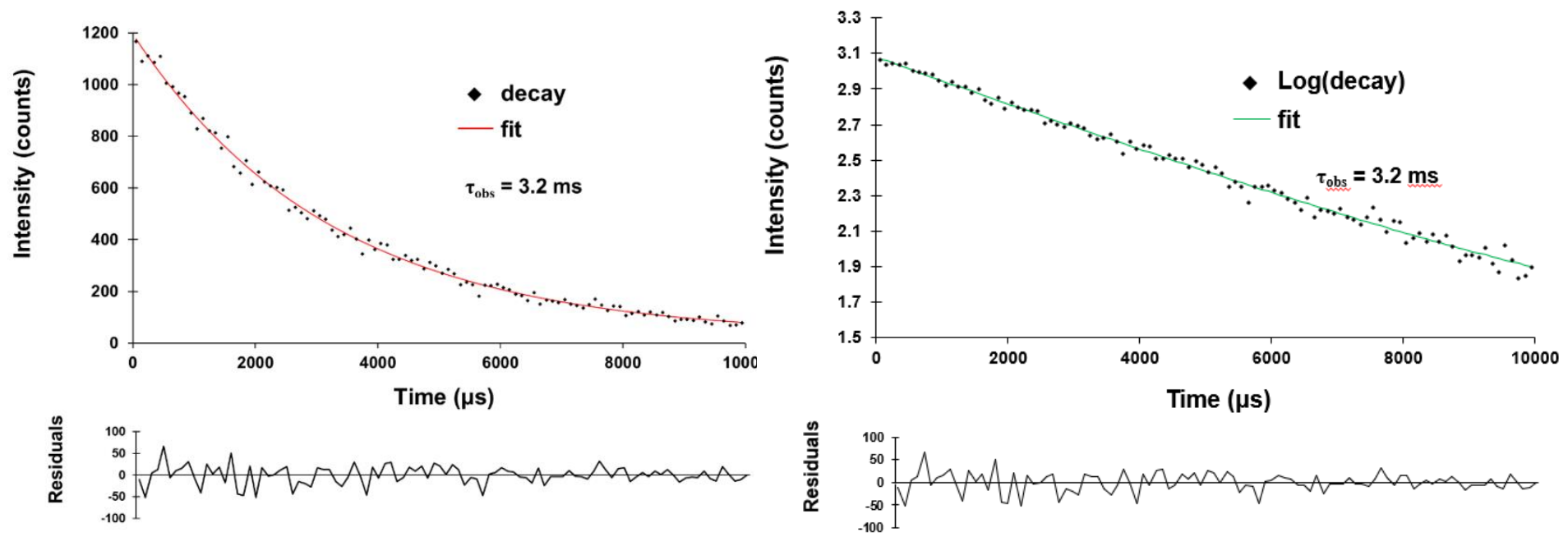

Figure S36: Lifetime exponential (left) and log (right) plots of (S,S)-terbium complex for $671 \mathrm{~nm}$. Excited with $280 \mathrm{~nm}$ LED, with a gate width of 4800 (10000 $\mu$ s window), $1450 \mu$ s delay, $1500 \mu$ s LED pulse width, and 300 events (points) taken over a $11500 \mu$ s total cycle time. Plot is an average of 30 individual runs for better resolution. The lifetime for the enantiomer is identical as expected. 

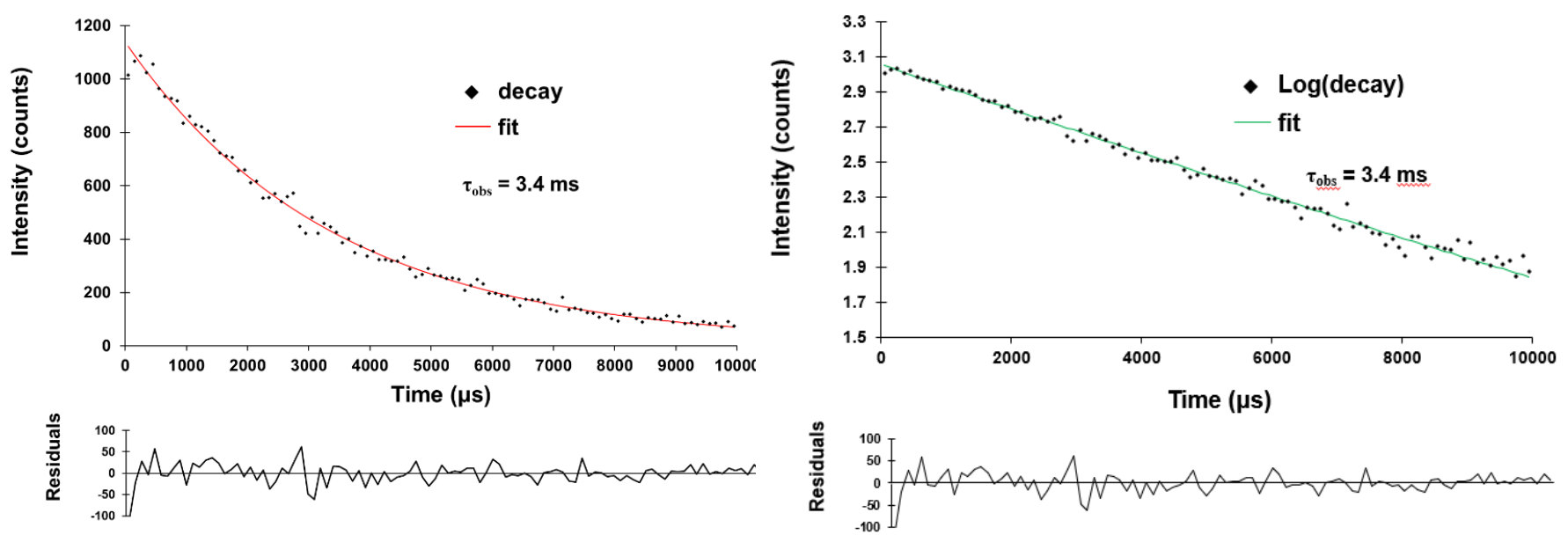

Figure S37: Lifetime exponential (left) and log (right) plots of (S,S)-terbium complex for $682 \mathrm{~nm}$. Excited with $280 \mathrm{~nm}$ LED, with a gate width of 4800 (10000 $\mu$ s window), $1450 \mu$ s delay, $1500 \mu$ s LED pulse width, and 300 events (points) taken over a $11500 \mu$ s total cycle time. Plot is an average of 30 individual runs for better resolution. The lifetime for the enantiomer is identical as expected.

\section{$((\mathbf{R}, \mathbf{R})$-tpdac $)$ Dy $(\text { OTf })_{3}$}
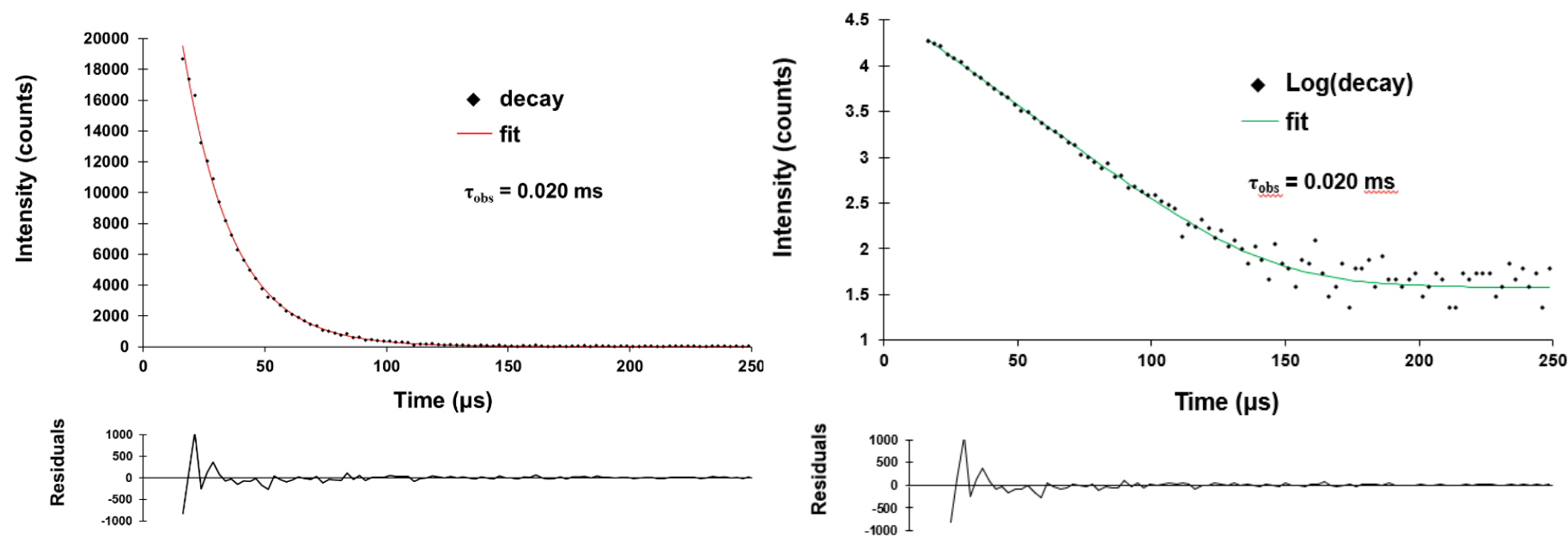

Figure S38: Lifetime exponential (left) and log (right) plots of (R,R)-dysprosium complex for $484 \mathrm{~nm}$. Excited with $280 \mathrm{~nm}$ LED, with a gate width of 120 (250 $\mu$ s window), $480 \mu$ s delay, $500 \mu$ s LED pulse width, and 1500 events (points) taken over a $1500 \mu$ s total cycle time. Plot is an average of 25 individual runs for better resolution. The lifetime for the enantiomer is identical as expected. 

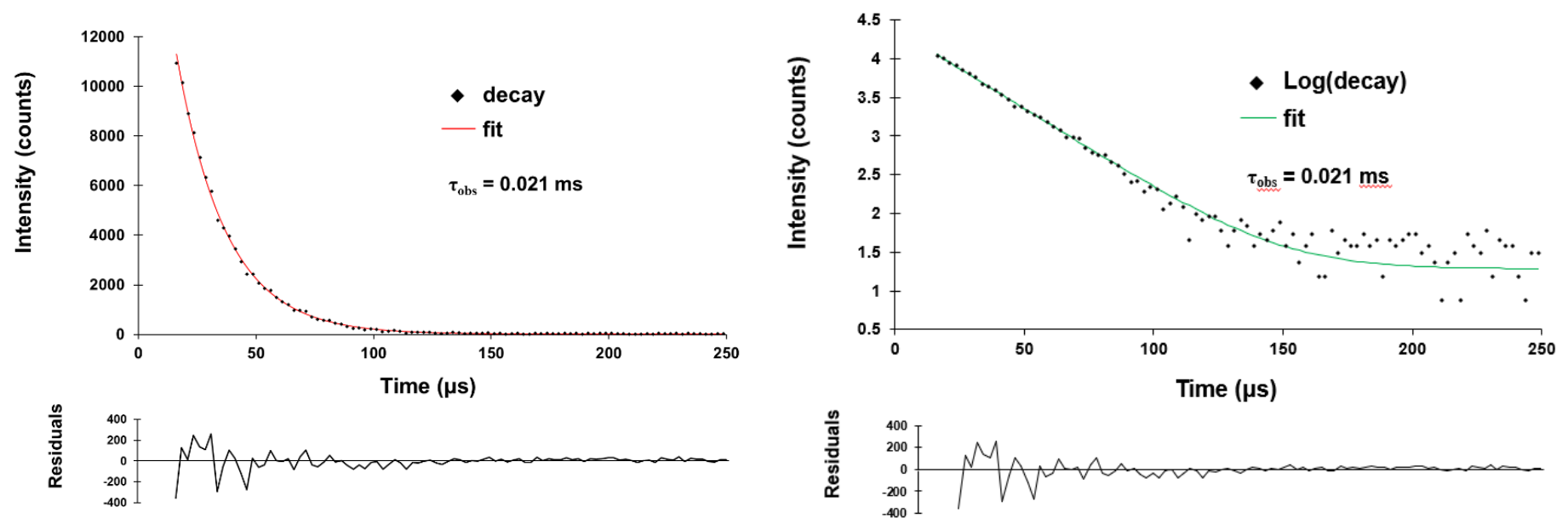

Figure S39: Lifetime exponential (left) and log (right) plots of (R,R)-dysprosium complex for $578 \mathrm{~nm}$. Excited with $280 \mathrm{~nm}$ LED, with a gate width of 120 (250 $\mu$ s window), $480 \mu$ s delay, $500 \mu$ s LED pulse width, and 1500 events (points) taken over a $1500 \mu$ s total cycle time. Plot is an average of 25 individual runs for better resolution. The lifetime for the enantiomer is identical as expected.

\section{$\underline{\text { Determination of } \eta_{\text {sens }} \text { for }(\mathbf{R}, \mathbf{R} \text {-tpdac }) \mathrm{Eu}(\mathbf{O T f})_{3}}$}

Using the following equation ${ }^{1}$ the $\eta_{\text {sens }}$ for Eu was calculated using its emission spectrum

$$
\frac{1}{\tau_{\text {rad }}}=\boldsymbol{A}_{M D, 0} n^{3}\left(\frac{I_{t o t}}{I_{M D}}\right) \text { (equation 1) }
$$

where $n$ is the refractive index of the solvent, $A_{\mathrm{MD}, 0}$ is the spontaneous emission probability for the ${ }^{5} \mathrm{D}_{0} \rightarrow{ }^{7} \mathrm{~F}_{1}$ transition in vacuo $\left(14.65 \mathrm{~s}^{-1}\right)$, and $I_{\mathrm{tot}} / I_{\mathrm{MD}}$ is the ratio of the total area of the corrected $\mathrm{Eu}^{3+}$ emission spectrum to the area of the ${ }^{5} \mathrm{D}_{0} \rightarrow{ }^{7} \mathrm{~F}_{1}$ band. ${ }^{2}$

Using this equation we arrive at a value of $12.1 \%$ sensitization efficiency for our $\mathrm{Eu}(\mathrm{III})$ complex, which is reasonable considering the low quantum yield. This equation is only effective for Eu, and not for the other lanthanide metals. The alternative is to use a modified Einstein equation ${ }^{2}$ for the other metals, however, we were unable to obtain the absorbance spectra of the lanthanide transitions for these metals ( $\mathrm{Tb}, \mathrm{Sm}, \mathrm{Dy})$ due to minor competing absorption and quenching of these transitions and therefore are unable to calculate for these complexes. 


\section{Determination of Solvation State for $(R, R-t p d a c) E u(O T f)_{3}$}

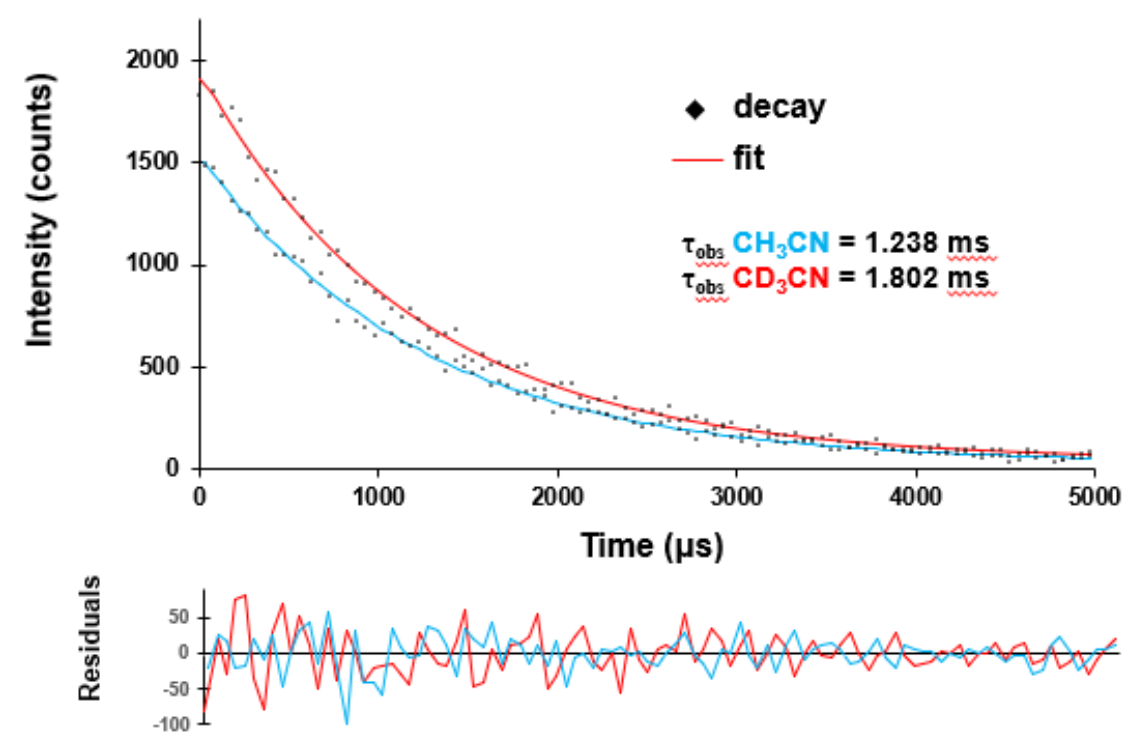

Figure S40: Lifetime decay curves and residuals plots for Eu complex at $619 \mathrm{~nm}$ at $4.63 \times 10^{-6} \mathrm{~mol} \mathrm{~L}^{-1}$ in $\mathrm{ACN}$ and $\mathrm{ACN}-\mathrm{d}_{3}$. Excited with $280 \mathrm{~nm}$ LED, with gate width of 2400 (5000 $\mu$ s window), $1000 \mu \mathrm{s}$ delay, $1000 \mu$ s LED pulse width, and 300 events (points) taken over a $6000 \mu$ s cycle time. Plot is an average of 35 individual runs for better resolution.

To discern the number of ACN molecules bound to the complex, the lifetime of the (R,R-tpdac)Eu(OTf $)_{3}$ was measured in both deuterated and non-deuterated ACN. The differences in lifetimes is consistent with no solvent molecules bound, and no displacement of the trifluoromethanesulfonate anions (Figure S40). ${ }^{3}$ 


\section{Horiba Duetta Correction Curve for Fluorescent Measurement}

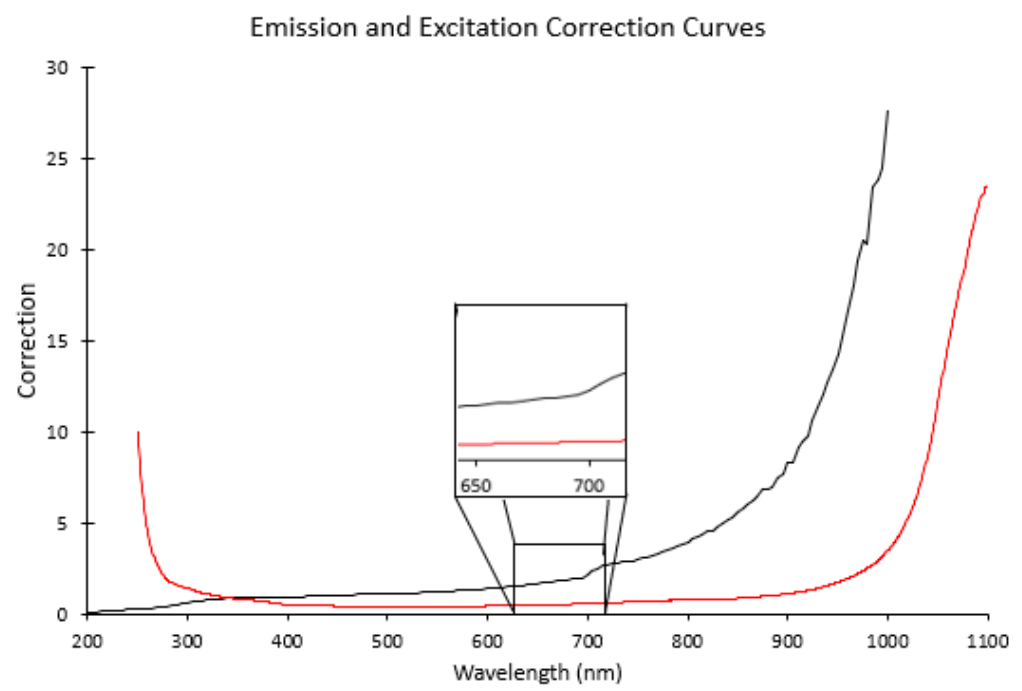

-Xcorrection - Mcorrection

Figure S41: Correction curves for the Eu fluorescence measurement where Xcorrection is for excitation and Mcorrection is for emission of the sample. The enhanced region demonstrates that in this region of the spectra there is no significant correction for the measurement which could affect the intensities of our Eu spectrum.

\section{$\underline{\text { Uncorrected Fluorescence of } \operatorname{Eu}((R, R) \text {-tpdac })(\mathrm{OTf})_{3}}$}

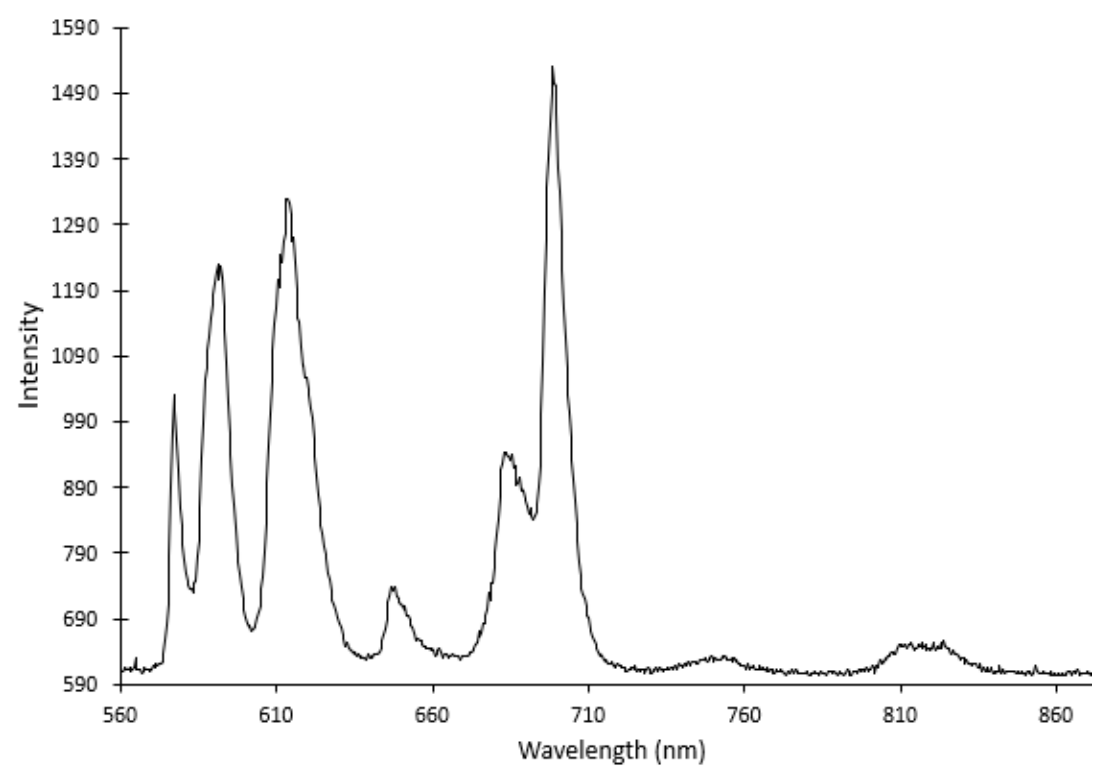

Figure S42: Uncorrected emission spectrum of europium complex demonstrating the relative intensity of the ${ }^{7} F_{4}$ transition remains the same. 


\section{Correction Information for the CPL Solo}

In the interest of ensuring our data was reliable, we acquired information from the manufacturer in order to strengthen the validity of our results. The CPL Solo by OLIS only works with raw data and numbers during acquisition. The PMTs sensitivity is wavelength dependent, but collection times are varied to enhance the signal to noise ratio for these areas without correction. The CPL Solo uses a direct digital method to acquire its data and leaves signals unaltered. The CPL signal is obtained as a direct calculation for glum using the following equation (equation 3):

$$
g_{\text {lum }}=\left(\frac{\left(f_{l}-f_{r}\right)}{\left[\frac{\left(f_{l}+f_{r}\right)}{2}\right]}\right)(\text { equation } 3)
$$

Where $\mathrm{fl}$ and fr are luminescence intensity of left and right-handed circularly polarized light, and the signals are divided by the average of the signal. In this manner the CPL signal is obtained quantitatively with no correction. The photon counter utilized for our instrument is rated for 230-870 nm and has an easy time acquiring data across the width of our spectra with around a 20 -fold increase in sensitivity.

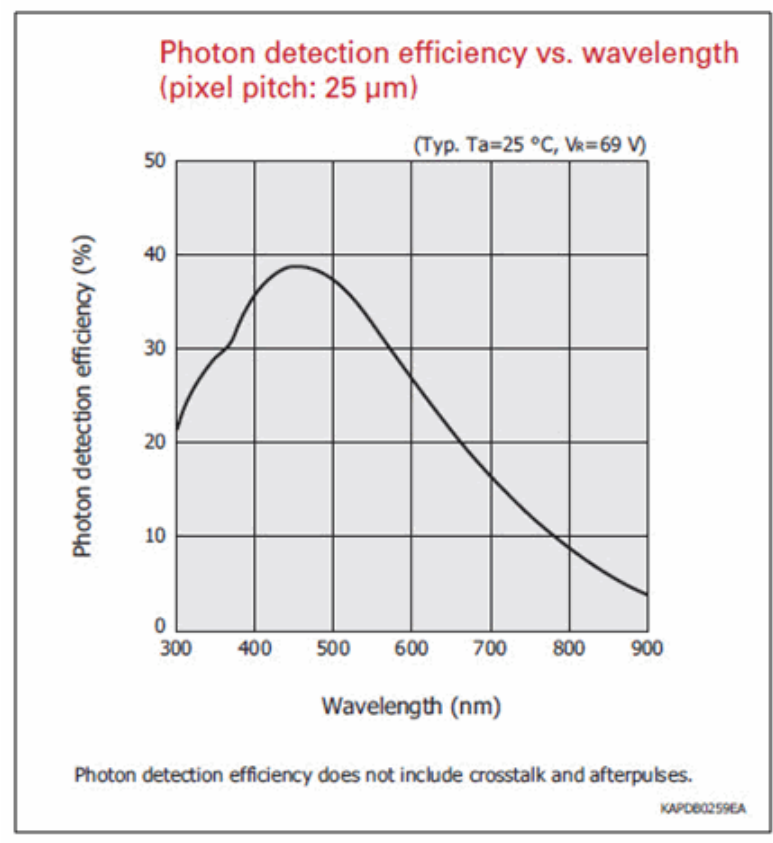

Figure S43: Curve provided by Hamamatsu for the photon detecting efficiency of our instrument. 


\section{Quantum Yield Determination}

Absolute quantum yields were determined by employing a barium sulfate coated integrating sphere using an Edinburgh FLS1000 fluorimeter. The integrating sphere was mounted on the fluorimeter with the entry and output ports of the sphere located in $90^{\circ}$ geometry from each other in the plane of the spectrometer. The quantum yields were determined directly using the Fluoracle Software. Using the integrating sphere, the quantum yield was measured to be $28.4 \%, 3.6 \%, 0.43 \%$, and $0.17 \%$ for $\mathrm{Tb}, \mathrm{Eu}, \mathrm{Dy}$, and $\mathrm{Sm}$ respectively. Because of the potential for error and for mis-calibration, we have measured the quantum yields using external standards according to the following equation:

$$
\phi_{L n}=\phi_{S t d}\left(\frac{m_{L n}}{m_{S t d}}\right)\left(\frac{\eta_{L n}}{\eta_{S t d}}\right)^{2}(\text { equation } 4)
$$

Where Std and Ln denote standard and sample, respectively; $\Phi$ is the quantum yield; $m$ is the slope from the plot of integrated emission intensity vs absorbance, and $\eta$ is the refractive index of the solvent. 9,10diphenylanthracene was utilized as standard. Quantum yields of $46.4 \%, 1.8 \%, 0.59 \%$ and $0.26 \%$ were measured for Tb, Eu, Dy. and Sm respectively. The results for Eu, Dy, and Sm are in line with the results obtained from the absolute method described above.
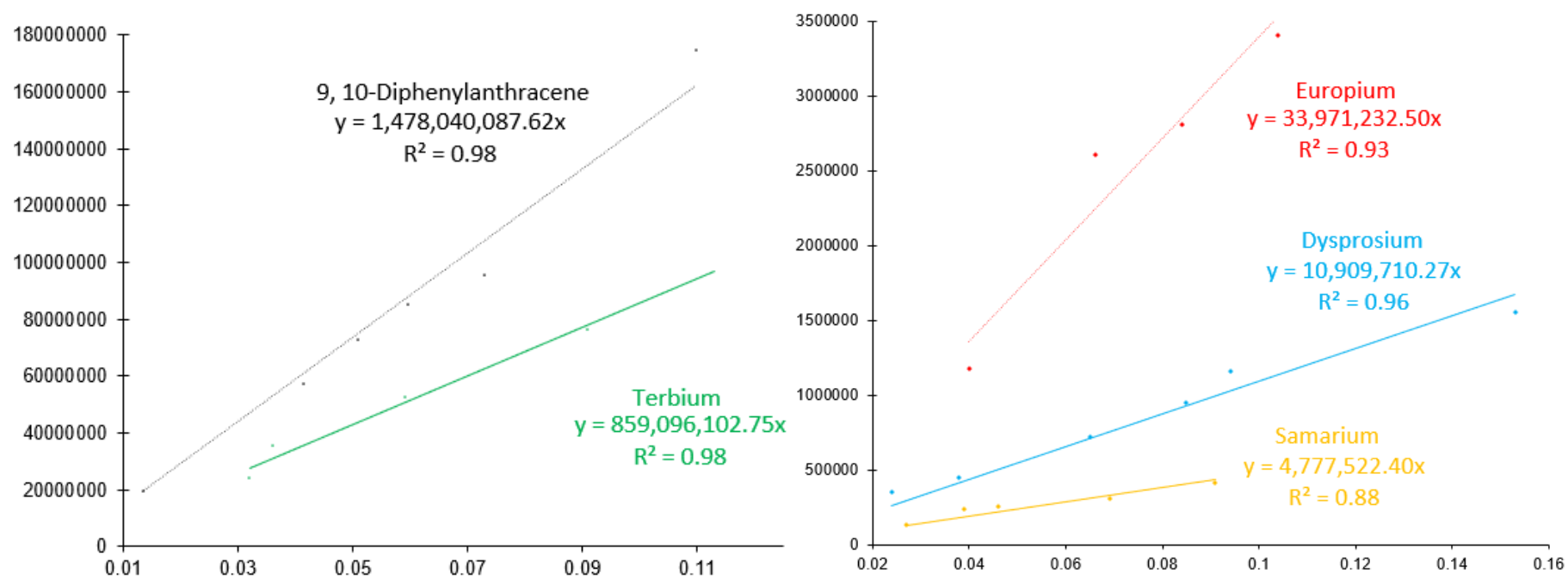

Figure S44: Titration curves of Emission spectrum integration vs absorbance at excitation wavelength $(277 \mathrm{~nm})$ for 9,10-diphenylanthracene external standard and lanthanide complexes.

For the Tb sample, due to the large discrepancy, a third method was used to verify the QY. Using a Horiba Fluoromax-Plus-C fluorimeter accompanied by the FluorEssence Software, with a barium sulfate coated integration sphere, the sample was measured again. The value obtained from this method agrees with the previously obtained value from the Edinburgh integrating sphere at 30.5\%. Because the estimated error of external quantum yield measurement is typically $10-15 \%$, we prefer disclosing the lower numbers obtained from the absolute method in the manuscript for Tb, Dy and Sm and from the secondary standard method for Eu. 
XRD

\section{(R,R-tpdac)Eu(OTf) 3}

Table S1: Crystal data and structure refinement for kma609_RRtpdacEu.

Identification code

Empirical formula

Formula weight

Temperature/K

Crystal system

Space group

$\mathrm{a} / \AA$

$\mathrm{b} / \AA$

c/Å

$\alpha /^{\circ}$

$\beta /{ }^{\circ}$

$\gamma /{ }^{\circ}$

Volume $/ \AA^{3}$

$\mathrm{Z}$

$\rho_{\text {calc }} \mathrm{g} / \mathrm{cm}^{3}$

$\mu / \mathrm{mm}^{-1}$

$\mathrm{F}(000)$

Crystal size $/ \mathrm{mm}^{3}$

Radiation
kma609_RRtpdacEu

$\mathrm{C}_{37} \mathrm{H}_{44} \mathrm{EuF}_{9} \mathrm{~N}_{6} \mathrm{O}_{11} \mathrm{~S}_{3}$

1167.92

100.01(10)

orthorhombic

$\mathrm{P} 2{ }_{12}{ }_{1} 1$

$10.02733(13)$

16.1985(2)

27.7142(5)

90

90

90

4501.54(12)

4

1.723

12.185

2352.0

$0.227 \times 0.061 \times 0.028$

$\mathrm{CuK} \alpha(\lambda=1.54184)$

6.32 to 147.222

$-12 \leq \mathrm{h} \leq 12,-17 \leq \mathrm{k} \leq 19,-24 \leq 1 \leq 33$

34870

$8940\left[\mathrm{R}_{\text {int }}=0.0582, \mathrm{R}_{\text {sigma }}=0.0530\right]$

$8940 / 79 / 625$

Data/restraints/parameters

Goodness-of-fit on $\mathrm{F}^{2}$

Final R indexes $[\mathrm{I}>=2 \sigma(\mathrm{I})]$

Final $\mathrm{R}$ indexes [all data]

Largest diff. peak/hole / e $\AA^{-3}$

Flack parameter

$$
1.044
$$

$\mathrm{R}_{1}=0.0427, \mathrm{wR}_{2}=0.1047$

$\mathrm{R}_{1}=0.0466, \mathrm{wR}_{2}=0.1068$

$1.07 /-1.30$

$-0.017(2)$ 


\section{$(\mathrm{S}, \mathrm{S}-\mathrm{tpdac}) \mathrm{Eu}(\mathrm{OTf})_{3}$}

Table S2: Crystal data and structure refinement for KMA577 SStpdacEuOTf.

Identification code

Empirical formula

Formula weight

Temperature/K

Crystal system

Space group

$\mathrm{a} / \AA$

$\mathrm{b} / \AA$

$\mathrm{c} / \AA$

$\alpha /{ }^{\circ}$

$\beta /{ }^{\circ}$

$\gamma /{ }^{\circ}$

Volume $/ \AA^{3}$

$\mathrm{Z}$

$\rho_{\text {calcg }} / \mathrm{cm}^{3}$

$\mu / \mathrm{mm}^{-1}$

$\mathrm{F}(000)$

Crystal size $/ \mathrm{mm}^{3}$

Radiation

$2 \Theta$ range for data collection $/{ }^{\circ}$

Index ranges

Reflections collected

Independent reflections

Data/restraints/parameters

Goodness-of-fit on $\mathrm{F}^{2}$

Final $\mathrm{R}$ indexes $[\mathrm{I}>=2 \sigma(\mathrm{I})]$

Final $\mathrm{R}$ indexes [all data]

Largest diff. peak/hole / e $\AA^{-3}$

Flack parameter
KMA577 SStpdacEuOTf

$\mathrm{C}_{37} \mathrm{H}_{44} \mathrm{EuF}_{9} \mathrm{~N}_{6} \mathrm{O}_{11} \mathrm{~S}_{3}$

1167.92

99.97(10)

orthorhombic

$\mathrm{P} 212121$

10.0253(3)

16.1917(5)

$27.7440(10)$

90

90

90

4503.6(3)

4

1.723

1.633

2352.0

$0.224 \times 0.165 \times 0.083$

$\operatorname{MoK} \alpha(\lambda=0.71073)$

4.778 to 60.6

$-14 \leq \mathrm{h} \leq 13,-22 \leq \mathrm{k} \leq 18,-36 \leq 1 \leq 36$

44483

$11995\left[R_{\text {int }}=0.0783, R_{\text {sigma }}=0.0942\right]$

$11995 / 79 / 625$

1.043

$\mathrm{R}_{1}=0.0565, \mathrm{wR}_{2}=0.0910$

$\mathrm{R}_{1}=0.0755, \mathrm{wR}_{2}=0.0967$

$1.82 /-1.85$

$-0.028(6)$

\section{Level B alert response:}

PLAT973_ALERT_2_B Check Calcd Positive Resid. Density on Eu1 1.61 eA-3A positive difference peak of $1.6 \mathrm{e} \cdot \AA^{-3}$ located near the Eu center remains after the final refinement. This small positive residual likely stems from Fourier truncation errors or small deficiencies in the face-index absorption correction model. 


\section{$($ rac-tpdac $) \operatorname{Eu}(\text { OTf })_{3}$}

Table S3: Crystal data and structure refinement for KMA576 ractpdacEuOTf.

\begin{tabular}{|c|c|}
\hline Identification code & KMA576 ractpdacEuOTf \\
\hline Empirical formula & $\mathrm{C}_{37} \mathrm{H}_{44} \mathrm{EuF}_{9} \mathrm{~N}_{6} \mathrm{O}_{11} \mathrm{~S}_{3}$ \\
\hline Formula weight & 1167.92 \\
\hline Temperature/K & $100.00(10)$ \\
\hline Crystal system & monoclinic \\
\hline Space group & $\mathrm{P} 2{ }_{1} / \mathrm{c}$ \\
\hline $\mathrm{a} / \AA ̊ \AA$ & $10.1588(3)$ \\
\hline $\mathrm{b} / \AA$ & $28.2483(8)$ \\
\hline$c / \AA ̊$ & $17.0441(4)$ \\
\hline$\alpha^{/ \circ}$ & 90 \\
\hline$\beta /{ }^{\circ}$ & $103.451(3)$ \\
\hline$\gamma /{ }^{\circ}$ & 90 \\
\hline Volume $/ \AA^{3}$ & $4757.0(2)$ \\
\hline $\mathrm{Z}$ & 4 \\
\hline$\rho_{\text {calcg }} / \mathrm{cm}^{3}$ & 1.631 \\
\hline$\mu / \mathrm{mm}^{-1}$ & 1.546 \\
\hline $\mathrm{F}(000)$ & 2352.0 \\
\hline Crystal size $/ \mathrm{mm}^{3}$ & $0.164 \times 0.138 \times 0.067$ \\
\hline Radiation & $\operatorname{MoK} \alpha(\lambda=0.71073)$ \\
\hline $2 \Theta$ range for data collection ${ }^{\circ}$ & 4.914 to 60.744 \\
\hline Index ranges & $-14 \leq \mathrm{h} \leq 9,-39 \leq \mathrm{k} \leq 39,-22 \leq 1 \leq 22$ \\
\hline Reflections collected & 67858 \\
\hline Independent reflections & $12975\left[\mathrm{R}_{\text {int }}=0.0628, \mathrm{R}_{\text {sigma }}=0.0629\right]$ \\
\hline Data/restraints/parameters & $12975 / 259 / 679$ \\
\hline Goodness-of-fit on $\mathrm{F}^{2}$ & 1.070 \\
\hline Final $\mathrm{R}$ indexes $[\mathrm{I}>=2 \sigma(\mathrm{I})]$ & $\mathrm{R}_{1}=0.0493, \mathrm{wR}_{2}=0.0914$ \\
\hline Final $\mathrm{R}$ indexes [all data] & $\mathrm{R}_{1}=0.0694, \mathrm{wR}_{2}=0.0975$ \\
\hline Largest diff. peak/hole / e $\AA^{-3}$ & $1.20 /-1.45$ \\
\hline
\end{tabular}

Level B alert response:

PLAT601_ALERT_2_B Structure contains solvent accessible voids of $133 \mathrm{~A}^{\wedge} 3$. The unit cell contains a void with volume $133 \mathrm{~A}^{\wedge} 3$, however no appreciable unmodeled density is observed. 


\section{Coordination Geometry about the Metal for Eu Species}

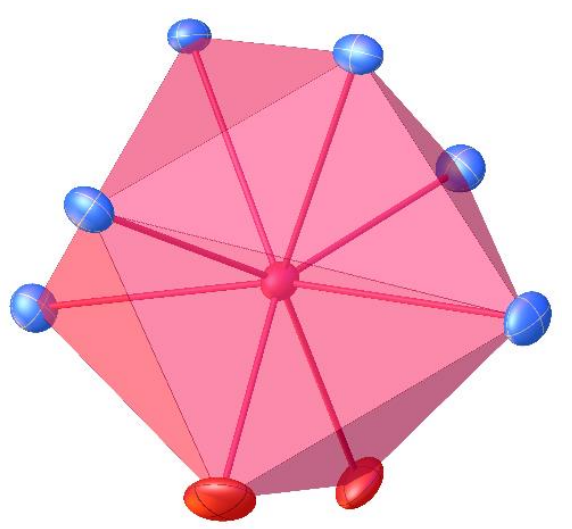

Figure S45: Bisdisphenoid polyhedron highlighting the coordination sphere around the europium center.

Red: oxygen, blue: nitrogen, pink: europium. 


\section{References}

(1) a) Bosshard, G. Z.; Brito, G. A.; Monteiro, J. H. S. K.; de Bettencourt-Dias, A.; Mazali, I. O.; Sigoli, F. A. Photophysical Properties of Asymmetric and Water-Soluble Dinuclear Lanthanide Complexes of Poly Glycol Chain Functionalized-Benzoic Acid Derivative: Experimental and Theoretical Approaches. RCS Adv., 2016, 6, 101133-101141. b) Johnson, K. R.; de Bettencourt-Dias, A. Inorg. Chem. 2019, 58, 13471-13480.

(2) Werts, M. H, V.; Jukes, R. T. F.; Verhoeven, J. W. The Emission Spectrum and Radiative Lifetime of $\mathrm{Eu}^{3+}$ in Luminescent Lanthanide Complexes. Phys. Chem. Chem. Phys. 2002, 4, 1542-1548.

(3) Stein, G.; Haas, Y. Pathways of Radiative and Radiationless Transitions in Europium(III) Solutions: Role of Solvents and Anions. J. Phys. Chem. 1971, 75, 3668-3677. 